\title{
AQÜÍFEROS FRATURADOS: UMA REVISÃO DOS CONDICIONANTES GEOLÓGICOS E DOS MÉTODOS DE INVESTIGAÇÃO
}

\author{
Amélia João FERNANDES
}

\begin{abstract}
RESUMO
A investigação detalhada dos condicionantes geológicos que regem a circulação de água em aqüíferos fraturados permite a elaboração de modelos conceituais os quais são imprescindíveis para um desenho adequado de testes hidráulicos e amostragens, cujos resultados, por sua vez, refinam os modelos conceituais. Este procedimento leva à previsão dos caminhos preferenciais de fluxo e assim à economia tanto de tempo como de recursos financeiros. No país ainda há pouca experiência no estudo de aqüíferos fraturados. Boa parte das investigações tem sido voltada à indicação de critérios para locação de poços e baseia-se na confrontação entre a capacidade específica ou vazão de poços e uma série de fatores (tais como lineamentos, litologias, compartimento topográfico, etc.) que, tradicionalmente, são considerados como sendo influentes sobre as produções. Recomenda-se aqui que os dados utilizados para a confrontação sejam apresentados na forma de distribuições acumuladas, pois a utilização de somente médias ou medianas, feita na maioria dos trabalhos, não é suficiente para separar populações de dados com comportamentos distintos, limitando a avaliação do alcance de resultados. Este tipo de estudo deveria constituir a análise preliminar do comportamento dos aqǘf́ros fraturados já que sugere as suas linhas gerais em escala de semi-detalhe ou regional. Mais recentemente e principalmente fora do país, têm sido desenvolvidos estudos que relacionam neotectônica e/ou campos de esforços atuais com a orientação de zonas de fraturas mais transmissivas, ou seja, com os caminhos preferenciais de fluxo. Estes têm concluído que tais fatores preponderam no controle sobre a circulação de água subterrânea. No entanto, a origem dos esforços que determinam a atitude das fraturas mais transmissivas ainda é assunto de debate e pode ter influências locais. Este trabalho apresenta uma síntese de fundamentos teóricos com relação a: fluxo de água subterrânea em meios fraturados, deformação rúptil e geração de fraturas extensionais, características geométricas das fraturas em função da litologia e da escala, e métodos diretos e indiretos de levantamento de fraturas. Além disso também apresenta uma análise de dados de poços com relação aos fatores que controlam o fluxo e indica métodos voltados à identificação dos caminhos preferenciais de circulação de água em meios fraturados.
\end{abstract}

Palavras-chave: aqüíferos fraturados, condicionantes geológicos, fraturas, deformação rúptil, tectônica

\begin{abstract}
Detailed investigation of the geological conditions that constrain the circulation of groundwater in fractured aquifers allows the elaboration of conceptual models which are necessary for the suitable design of hydraulic tests and sampling, whose results, in turn, improve the conceptual models. This procedure leads to the prediction of the preferential flow pathways and, therefore, saves time and diminishes costs. In Brazil there is still little experience in the study of fractured aquifers. The majority of the investigations have dealt with the indication of criteria for the location of wells
\end{abstract}


and are based on the relation between specific capacity or discharge and a number of factors, such as lineaments, lithology, topographic setting, etc., that traditionally are thought to be influential in well production. It is herein suggested that well production data be presented in the form of cumulative distributions, as average and median values alone, as presented in the majority of studies, are not enough to separate data populations of distinct behaviour and limit assessment of the results. This type of study should be conducted as a preliminary evaluation, as it suggests the general outline of the behaviour of the fractured aquifer at regional and semi-detailed scales. More recently, and mainly outside of the country, studies have also been conducted that relate neotectonics and/or current stress fields with the orientation of transmissive fracture zones, that is, with preferential flow pathways,. These have concluded that recent or current tectonics are the predominant control on the circulation of groundwater. However, the origin of the stresses that determine the attitude of the more transmissive fractures is still a matter of debate and may be influenced by local factors. The present work provides a synthesis of theoretical fundamentals with regard to groundwater flow in fractured aquifers, brittle deformation and generation of extensional fractures, geometric characteristics of fractures as a function of scale and lithology, and direct and indirect methods of fracture survey. Furthermore, this work also presents an analysis of well data regarding the factors that control flow and indicates methods for identifying preferential flowpaths in fractured media.

Keywords: fractured aquifers, geological constraints, fracture, brittle deformation, tectonics

\section{INTRODUÇÃO}

A investigação detalhada dos condicionantes geológicos que regem a circulação de água em aqǘfferos fraturados permite inferir caminhos preferenciais de fluxo, possibilitando a elaboração de modelos conceituais e, consequentemente, o desenho adequado de testes hidráulicos e amostragens, os quais retro-alimentam os modelos. Com isto, tanto tempo como recursos financeiros são economizados.

No país boa parte das investigações tem sido voltada à indicação de critérios para locação de poços e baseia-se na confrontação entre a capacidade específica ou vazão de poços e uma série de fatores (tais como lineamentos, litologias, compartimento topográfico, etc.) que, tradicionalmente, são considerados como sendo influentes sobre as produções. Este tipo de estudo deveria constituir a análise preliminar do comportamento dos aqüíferos fraturados já que sugere as suas linhas gerais em escala de semidetalhe ou regional. Mais recentemente e principalmente fora do país, têm sido desenvolvidos estudos que relacionam neotectônica e/ou campos de esforços atuais com a orientação de zonas de fraturas mais transmissivas, ou seja, com os caminhos preferenciais de fluxo.

O objetivo deste trabalho é apresentar uma síntese de trabalhos publicados que vão desde a análise da produção de poços até investigações hidrogeológicas detalhadas e o que eles trazem de avanço sobre o conhecimento dos condicionantes geológicos mais efetivos de fluxo de água nestes meios.

O trabalho foi subdividido nos seguintes temas: fundamentos teóricos da circulação de água em aqüíferos fraturados; deformação rúptil e a geração de fraturas extensionais; geometria das fraturas de acordo com a escala e a litologia; métodos diretos e indiretos de levantamento e caracterização das redes de fraturas; e análise de dados de poços para o entendimento do comportamento de aqüíferos fraturados. No último item são apresentadas conclusões e recomendações. $\mathrm{O}$ entendimento de como e quando as fraturas extensionais são geradas é enfatizado no presente trabalho, pois constitui elemento chave para a determinação dos caminhos preferenciais de fluxo em aqǘferos fraturados. No entanto, as fraturas de cisalhamento, a princípio, não podem ser negligenciadas, como se verá adiante. 


\section{FLUXO DE ÁGUA SUBTERRÂNEA EM MEIOS FRATURADOS}

A quantidade, ou mesmo a existência, de fluxo de água subterrânea através de rocha sã de baixa porosidade primária vai depender da densidade, conectividade e abertura das fraturas presentes (DOMENICO \& SCHWARTZ 1990).

A análise do fluxo da água segundo fraturas pode seguir dois tipos de abordagem: meio contínuo e meio descontínuo. Quando se utiliza a abordagem do meio contínuo tem que se substituir o meio fraturado por um meio contínuo representativo onde os valores de condutividade hidráulica, porosidade e compressibilidade são definidos (DOMENICO \& SCHWARTZ 1990). $\mathrm{O}$ volume de rocha necessário para a definição destes parâmetros, e ao qual é possível aplicar a lei de Darcy, é denominado de volume elementar representativo (representative elementary volu$m e$ ) ou VER (FREEZE \& CHERRY 1979). Em rochas fraturadas este volume pode chegar a valores muito grandes ou mesmo nem existir. Por este motivo, a abordagem de meio descontínuo, onde é analisada a hidráulica do fluxo de fraturas individuais, é considerada a mais adequada pois constata-se que algumas fraturas individuais ou zonas de fraturas estreitas são muito mais condutoras e fornecem os caminhos preferenciais

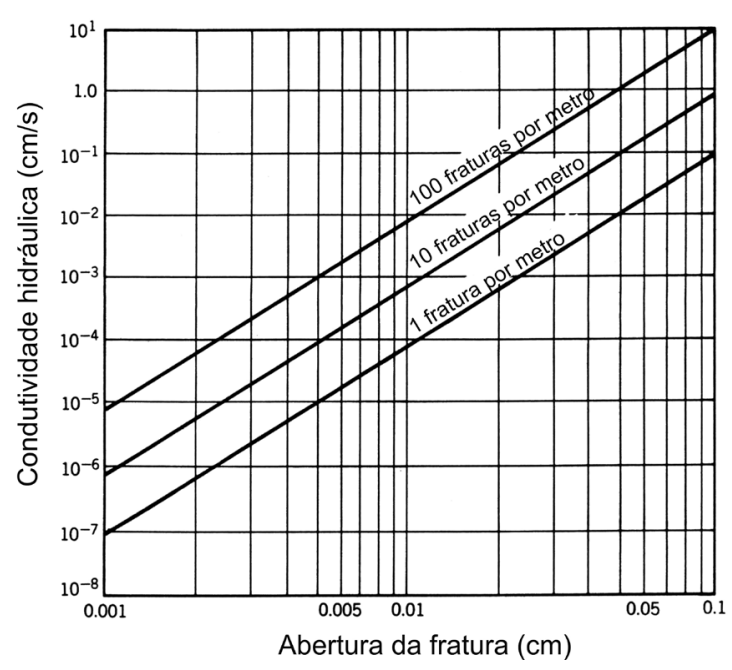

FIGURA 1 - Influência da abertura (b) e do espaçamento de fraturas sobre a condutividade hidráulica ao longo de um grupo de fraturas paralelas e lisas (modificado de HOEK \& BRAY 1981, apud DOMENICO \& SCHWARTZ 1990). para a circulação e transporte de contaminantes (NOVAKOWSKI 1995), além de constituirem as entradas de água que contribuem para produções mais elevadas de alguns poços (BERTACHINI 1987, MENEGASSE 1991, BANKS et al. 1994, LOISELLE \& EVANS 1995).

A condutividade hidráulica pode ser calculada para um grupo de fraturas planares e lisas pela equação desenvolvida por SNOW (1968 apud FREEZE \& CHERRY 1979) e denominada de lei cúbica:

$$
K=\frac{\rho \cdot g}{12 \mu} \cdot N b^{3}
$$

Onde $\rho$ e $\mu$ são a densidade e viscosidade da água, g, aceleração da gravidade, N, o número de fraturas por unidade de distância e $b$, a sua abertura. A equação acima não leva em consideração a rugosidade presente em fraturas encontradas na natureza e aplica-se aos casos onde a lei de Darcy é válida (fluxo linear e laminar).

A lei cúbica mostra que a abertura da fratura (b) é mais importante que a densidade de fraturas $(\mathrm{N})$ na determinação da condutividade hidráulica, pois a primeira é proporcional ao cubo da abertura e a segunda apenas diretamente proporcional à densidade das fraturas (Figura 1). Dados de poços indicam que a produção é relativamente independente do número de fraturas atravessadas (GALE \& ROULEAU 1983, BRIZKISHORE 1993) (Figura 2).

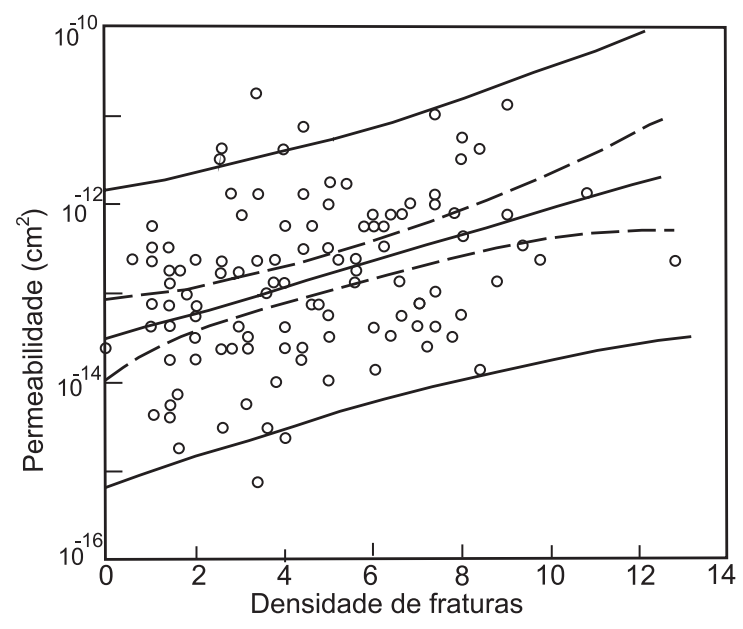

FIGURA 2 - Gráfico mostrando correlação muito tênue entre densidade de fraturas e permeabilidade indica que a produção é relativamente independente do número de fraturas atravessadas (modificado de GALE \& ROULEAU 1983). 


\section{DEFORMAÇÃO RÚPTIL E GERAÇÃO DE FRATURAS EXTENSIONAIS}

A abertura das fraturas é determinada pelo mecanismo de sua propagação (LAWN \& WILSHAW 1975), que pode ser de 3 tipos (Figura 3):

I - Por abertura (opening) ou separação normal dos planos de ruptura sob a ação de esforço de tração.

II - Por deslizamento paralelo à superfície das fraturas e à frente de propagação da ruptura.

III - Por deslizamento paralelo à superfície das fraturas e perpendicular à frente de propagação da ruptura.

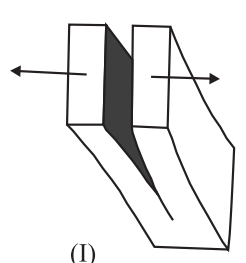

(I)

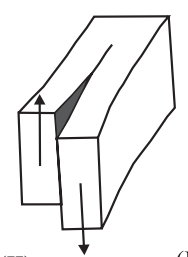

(II)

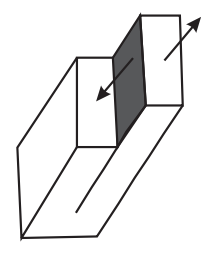

(III)

FIGURA 3 - Modos de propagação de fraturas por extensão perpendicular à superfície da fratura (I) e por deslizamento paralelo à superfície de fratura, podendo ser paralelo (II) ou perpendicular (III) à frente de propagação. Adaptado de LAWN \& WILSHAW (1975).

As fraturas do modo I propagam-se perpendicularmente ao esforço mínimo principal, e podem ser de dois tipos: de extensão, que se formam quando o esforço mínimo principal (б3) é negativo, e hidrofraturas, que se formam quando a pressão total de fluidos for igual à soma do esforço mínimo principal (o3) com a resistência à tração da rocha. As primeiras são limitadas a profundidades rasas em áreas que estão sofrendo extensão ativa, tais como riftes (GUDMUNDSSON 1992), enquanto as hidrofraturas podem se formar em qualquer profundidade (GUDMUNDSSON et al. 2003), tanto sob regimes compressivos como extensivos (POLLARD \& AYDIN 1988). Elas comumente se iniciam em heterogeneidades que controlam a resistência de materiais rígidos, como fósseis, clastos, marcas de sola, poros e microquebras. Quando uma massa rochosa, com qualquer arranjo de "defeitos" destes tipos, é submetida a esforços elevados ocorre uma concentração dos mesmos, particularmente na extremidade destas feições, havendo propagação da ruptura (RA-
MSAY \& HUBER 1987, POLLARD \& AYDIN 1988). Por meio deste mecanismo, fraturas préexistentes e dispostas perpendicularmente a $\sigma 3$, tenderiam a sofrer abertura. $\mathrm{O}$ próprio incremento da pressão de fluidos por vários processos, como rápido enterramento de sedimentos, deformação tectônica ou agitação súbita (terremotos), também pode fazer com que a rocha que se encontra inicialmente em situação de estabilidade passe para situação de geração ou reativação de fraturas (RAMSAY \& HUBER 1987).

Estruturas plumosas (plume) e do tipo "costela" (rib) são feições diagnósticas do mecanismo de tração, pois são comumente encontradas nas superfícies de fraturas extensionais. As feições plumosas são mais complexas e desenvolvem-se em fraturas que se propagam relativamente rápido (PRICE \& COSGROVE 1990).

A geração de fraturas por cisalhamento ocorre sob esforço diferencial ( $\sigma 1-\sigma 3)$ compressivo e a propagação se dá pela coexistência dos dois modos fundamentais de ruptura (SCHOLZ 1989, apud DAVISON 1994). Aparentemente o fraturamento macroscópico é determinado pela densidade de microquebras geradas pelo modo I, que se formam paralelamente ao $\sigma 1$. Estas são responsáveis pela dilatação que ocorre aproximadamente a meio caminho do esforço de fraturamento.

As condições de esforços sob as quais se dá o fraturamento são representadas pelos círculos de Mohr (Figura 4). Da figura 4Aiii deduz-se que as fraturas de cisalhamento ocorrem em dois planos conjugados, orientados simetricamente em relação a $\sigma 1$. Quando o esforço diferencial é negativo (Figura 4Ai) e igual à resistência trativa da rocha $(\mathrm{T})$, formam-se fraturas extensionais. Em situações intermediárias formam-se fraturas híbridas com $2 \theta$ menor que o das fraturas conjugadas (Figura 4Aii). Para se distinguir entre fraturas conjugadas e híbridas é necessário considerar o ângulo $2 \theta$ entre elas e as variações deste ângulo com a litologia afetada (HANCOCK 1985, DUNNE \& HANCOCK 1994). Para os estados de esforços em que o esforço diferencial é menor que 4T e em que os círculos de Mohr tocam a envoltória de deformação (Figura 4b) serão geradas fraturas extensionais. No entanto, dependendo da magnitude do esforço diferencial, (desde um pouco menos que 4T, círculo i, a zero, círculo iv) as fraturas extensionais resultantes terão desde uma única orientação bem definida a orientações totalmente aleatórias (COSGROVE 1998). 
(a)

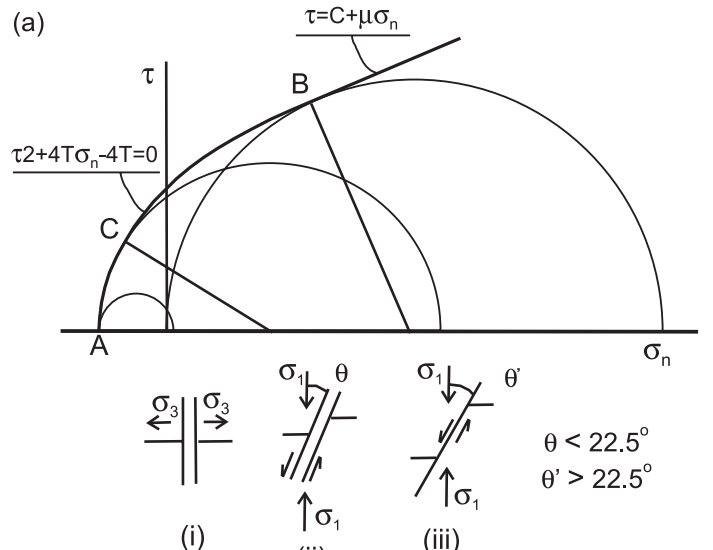

(b)

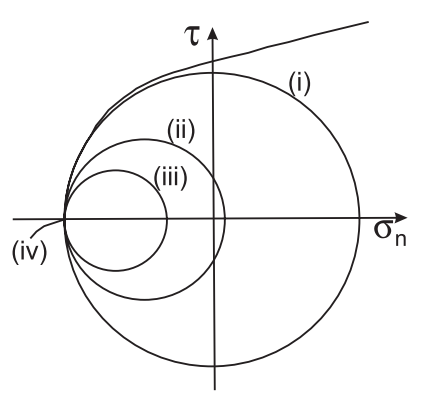

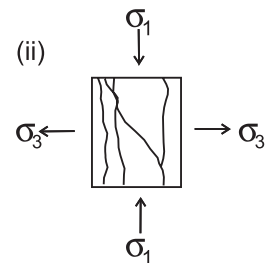

(iii)

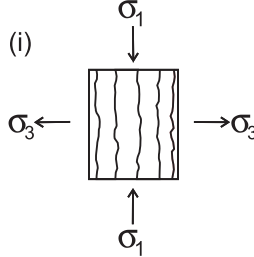

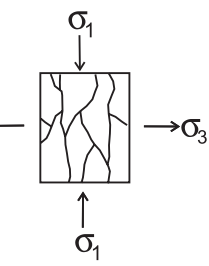

(iv)

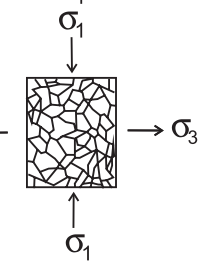

FIGURA 4 - a) Círculos de esforços de Mohr representando condições que originam fraturas de tração (i), de cisalhamento (ii) e híbridas (iii). Também é ilustrado o sentido de movimento dos planos de fratura e sua orientação com relação aos eixos dos esforços

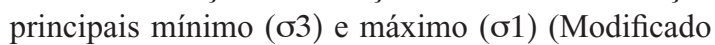
de PRICE \& COSGROVE 1990). b) Orientação das fraturas extensionais para esforços diferenciais que variam desde ligeiramente menores que $4 \mathrm{~T}$ (i) a zero (iv). No primeiro caso as fraturas apresentam uma única orientação bem definida, pois são perpendiculares a $\sigma 3$ que é muito menor que $\sigma 1$. Conforme $\sigma 1 \mathrm{e}$ $\sigma 3$ passam a ter magnitudes cada vez mais próximas, as fraturas extensionais passam gradativamente a se formarem em mais direções, chegando ao caso extremo $(\sigma 1=\sigma 3)$ onde padrões aleatórios são gerados (iv) (Adaptado de COSGROVE 1998).

A atuação da pressão de fluidos é ilustrada pelo círculo de Mohr na figura 5, na qual são apresentados três círculos que não tocam a envoltória de deformação, representando, portanto, campos estáveis de esforços. No entanto, tais círculos podem ser deslocados para a esquerda pela atuação de pressão de fluidos, até que interceptem a envoltória de deformação, quando o fraturamento hidráulico irá ocorrer. Pode-se notar que o estado de esforços (i) causará deformação por cisalhamento, (ii) fraturas extensionais paralelas e (iii) brechação, pela formação de arranjo quase aleatório de fraturas extensionais. Fica claro que o fraturamento hidráulico pode gerar tanto fraturas extensionais (desde aleatoriamente orientadas até com uma única direção bem definida) como fraturas de cisalhamento (COSGROVE 1998). Para campos de esforços em que $\sigma 1$ é vertical, a relação de magnitude dos esforços principais $(\sigma 1, \sigma 2$ e $\sigma 3)$ pode levar à formação de diversos arranjos tridimensionais, tanto de fraturas extensionais, como de cisalhamento. Quando os dois esforços horizontais principais são de diferente magnitude será gerado um único grupo de fraturas paralelas, sendo verticais para $\sigma 1-\sigma 3<4 \mathrm{~T}$ (fraturas extensionais) e de mergulhos médios para $\sigma 1-\sigma 3>4 \mathrm{~T}$ (fraturas de cisalhamento). Quando $\sigma 2=\sigma 3$, as fraturas apresentarão direções aleatórias, sendo verticais para $\sigma 1-\sigma 3<4 \mathrm{~T}$, e de mergulho médio para o1- $\sigma 3>4$ T (COSGROVE 1998).

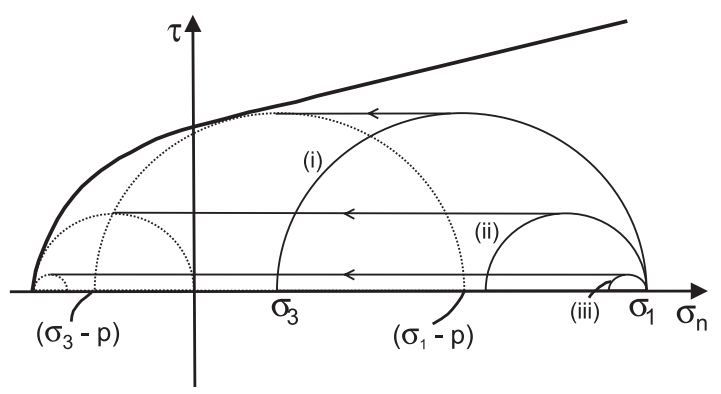

FIGURA 5 - Resultado da atuação da pressão de fluidos em condições distintas de esforços diferenciais ( $\sigma 1-\sigma 3)$ levando à geração de fraturas hidráulicas por cisalhamento (i), fraturas extensionais paralelas (ii) e formação de um arranjo quase aleatório de fraturas extensionais (iii) (Adaptado de COSGROVE 1998).

A posição espacial das fraturas de tração (e mais abertas) e das de cisalhamento depende do regime tectônico (extensional, compressivo ou transcorrente) que atuou ou atua em uma dada 


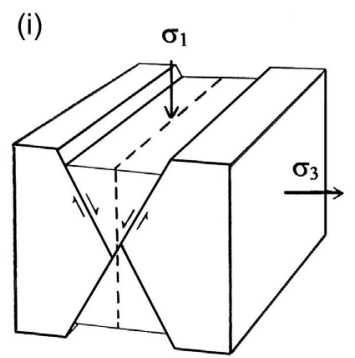

(ii)

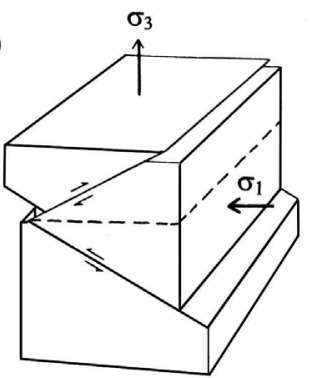

(iii)

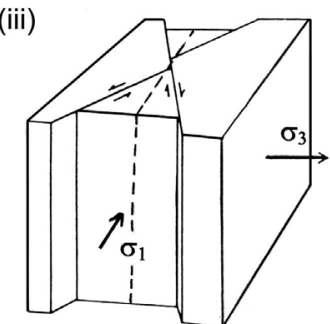

FIGURA 6 - Regimes tectônicos e posição espacial de fraturas extensionais de maior abertura (linha tracejada) e de cisalhamento (linha contínua e movimento indicado por flechas): (i) regime extensional, (ii) compressivo e (iii) transcorrente (adaptado de RAMSAY \& HUBER 1987).

região (Figura 6). Para os regimes extensional e transcorrente (Figura 6i e iii) as fraturas de tração serão verticais e para o compressivo (Figura 6ii) horizontais, sempre paralelas ao esforço máximo principal $(\sigma 1)$ e perpendiculares ao esforço mínimo principal $(\sigma 3)$.

\section{CARACTERÍSTICAS GEOMÉTRICAS DAS FRATURAS EM FUNÇÃO DA LITOLOGIA E DA ESCALA}

As propriedades das redes de fraturas variam da escala local (p. ex., de poço) às de semi-detalhe (p. ex., de microbacias hidrográficas) ou regionais, o que acarreta mudanças no fluxo de água subterrânea. ROULEAU et al. (1996) mostram que em ortoquartzito fraturado cortado por sistema ortogonal de fraturas subverticais, o fluxo é controlado na escala de campo por fraturas de origem tectônica. No laboratório, a presença de descontinuidades sub-horizontais de origem primária ou diagenética resulta em valores significativamente maiores de $\mathrm{K}$ horizontal para as amostras-testemunho. Assim, o tipo, origem e geometria das estruturas que afetam o fluxo são diferentes de uma escala para a outra.
ODLING (1997) abordou a questão da escala a partir do mapeamento de traços de fraturas. Os mapas obtidos indicam uma distribuição de potência para o comprimento das fraturas. Esta distribuição, válida para 4 ou mais ordens de grandeza, implica em um decréscimo da conectividade aparente com o decréscimo da escala, concluindo-se que somente as orientações dos grupos de fraturas principais podem ser consideradas como independentes da escala. Todas as outras propriedades (distribuição de comprimentos, densidade, conectividade e natureza das junções) são dependentes da escala. ROULEAU \& GALE (1985) encontraram diferenças apreciáveis entre grupos de fraturas em relação às densidades e às distribuições de comprimento de traço. A distribuição log-normal ajustouse muito bem a todos os dados dos grupos de fraturas para um nível de significância maior que 0,15 . ZAHNG et al. (2004), por outro lado, verificaram distribuições exponencial negativa e normal para espaçamento e comprimento do traço de fraturas, respectivamente.

Conforme se deduz a partir dos dados acima, as distribuições de frequência podem variar de região para região e sua determinação é muito importante para a extrapolação e modelagem de redes de fraturas, implicando em um poder de predição do comportamento do aqüífero; apesar de condutividades hidráulicas mais elevadas serem restritas a poucas fraturas, o armazenamento e comportamento do aqüífero a longo prazo é regido pela densidade e conectividade da rede de fraturas. Assim, como apontado por ODLING et al. (1999), tais propriedades variam com a escala e este fator deve ser considerado quando se almeja extrapolações para regiões maiores. Neste sentido, a teoria dos fractais tem sido uma das ferramentas exploradas por diversos autores (LONG 1996), embora ainda seja um campo de estudos a ser consolidado.

Ainda com relação à configuração da rede de fraturas, sabe-se que o acamamento litológico também é um fator muito importante, condicionando a existência dos seguintes membros finais para os tipos de rede de fraturas: (1) sistemas limitadospor-estratos (stratabound) onde as fraturas são confinadas a camadas individuais, os tamanhos são condicionados pela espessura da camada e o espaçamento é regular; (2) sistemas não-limitadospor-estratos (non-stratabound), nos quais as fraturas mostram um amplo intervalo de tamanhos (freqüentemente do tipo potência), são espacialmente agrupados (clustered) e verticalmente persistentes (ODLING et al. 1999). Na natureza existem varia- 
ções e combinações entre estes dois extremos e em um mesmo sistema pode haver intercâmbio de um para outro, de acordo com o intervalo de escalas. Em termos de implicações para o fluxo, nos sistemas limitados-por-estratos o fluxo transversal às camadas pode ser inibido e assim, a permeabilidade paralela às mesmas pode ser muito maior que a transversal. Exemplo marcante deste caso corresponde aos basaltos da Formação Serra Geral, cujas principais descontinuidades permeáveis foram bem caracterizadas nos estudos desenvolvidos para a construção de barragens principalmente nos estados de São Paulo e Paraná. Estes estudos demonstram que as estruturas permeáveis correspondem, na grande maioria das vezes, a zonas de fraturas sub-horizontais, muitas vezes próximas aos contatos entre derrames, mas também situadas em meio às porções centrais de basaltos densos (SINELLI 1971, REBOUÇAS 1978, BJORNBERG \& KUTNER 1983, NAKAO et al. 1983, QUADROS et al. 1991, FERNANDES et al. 2008 a, b). A estratificação é fator de grande importância em bacias sedimentares com intercalação de tipos litológicos com propriedades mecânicas distintas, como exemplificado por MORIN \& SAVAGE (2003) e GROSS (1993, apud ENGELDER et al. 1993). Em litologias de textura mais fina (siltitos e lamitos), fraturas horizontais (ou partições) podem ser produzidas ao longo dos planos de acamamento. A transmissividade destas é grande próximo à superfície, mas diminui muito a partir dos 10 a $25 \mathrm{~m}$ de profundidade (MORIN $\&$ SAVAGE 2003). Por outro lado as fraturas verticais, formadas em litologias mais competentes ( $p$. ex., calcários e arenitos), tem transmissividade independente da profundidade, embora dependam da sua orientação com relação ao campo de esforços atual (MORIN \& SAVAGE 2003). A intercalação de dolomitos e folhelhos/lamitos pode ocasionar partição da deformação rúptil com desenvolvimento simultâneo, sob um único campo de esforços, de fraturas extensionais e veios (modo I) nos primeiros, e fraturas de cisalhamento (modos II e III) nos últimos (GROSS 1993, apud ENGELDER et al. 1993). Isto ocorre devido às propriedades mecânicas (relação de Poisson, v, e resistência ao cisalhamento, $\tau_{\mathrm{o}}$ ) distintas destes tipos litológicos e à atuação da pressão de fluidos.

Nos sistemas de fraturas não-limitados-porestratos as fraturas penetram muitas camadas e contrastes grandes de permeabilidade paralela ou perpendicular às camadas são menos prováveis (ODLING et al. 1999).

\section{MÉTODOS DIRETOS E INDIRETOS DE LEVANTAMENTO E CARACTERIZAÇÃO DAS CARACTERÍSTICAS GEOMÉTRICAS DAS FRATURAS}

Os métodos diretos consistem no levantamento de fraturas em exposições de rocha. Levantamentos sistemáticos de fraturas, em geral, são feitos ao longo de scanlines ou grids (ROULEAU 1994) e incluem as seguintes informações: natureza da fratura (extensão ou cisalhamento), direção e mergulho (a atitude da fratura serve para discriminar grupos de fraturas), comprimento e espessura do traço, número e natureza de terminações visíveis, rugosidade, ondulação, material de preenchimento, orientação dos indicadores cinemáticos e uma medida qualitativa da quantidade de água que flui ao longo de cada fratura (ROULEAU \& GALE 1985, LACHMAR 1994, TAVCHANDJIAN et al. 1997). GERNANDT \& HEIDTMAN (1997) classificam as fraturas identificadas em testemunhos em termos do seu significado hidráulico aparente. Por exemplo, as fraturas do tipo $\mathrm{X}$ apresentam profundo intemperismo ao longo de sua superfície, sugerindo que constituam os principais caminhos do fluxo, e as do tipo $\mathrm{C}$, que permanecem não quebradas em testemunhos e sem nenhum sinal de intemperismo, devem ser as menos propícias ao fluxo. Aplicação do método de scanlines também foi descrito em FERNANDES \& ROULEAU (2008) para os basaltos de Ribeirão Preto. Deslocamentos ao longo de fraturas individuais, pertencentes a uma rede, foram simulados com base nos dados coletados ao longo de scanlines. Isto resultou na indicação de fraturas mais e menos permeáveis, dependendo dos tipos de movimento observados (fechamento e cisalhamento). A posição atual dos esforços principais ( $\sigma 1, \sigma 2$ e $\sigma 3)$, deduzida a partir de levantamentos e análise de dados estruturais, foi um dado de entrada fundamental para as simulações (FERNANDES \& ROULEAU 2008).

Os métodos indiretos de identificação e caracterização de fraturas vão desde a interpretação de lineamentos em fotografias aéreas e imagens de satélite, radar ou aerogeofísicas, até geofísica de superfície e de poço.

Em termos de geofísica de superfície, os métodos de resistividade, sondagem elétrica vertical (SEV) e caminhamento elétrico (CE) têm sido os mais aplicados para o estudo de aqüíferos em função da sua fácil utilização e simplicidade dos equipamentos. Estes métodos podem indicar as profundidades do nível d'água e do contato entre mate- 
rial inconsolidado e rocha sã, contatos litológicos entre rochas com condutividades elétricas distintas e fraturas com maior fluxo de água ou com grande conteúdo de argila (KELLY \& MARES 1993; MENDES \& DEHAINI 1996; MORIN et al. 1997, 2000; MORIN \& SAVAGE 2003; GALLAS 2003). Uma falha na rocha sã corresponde normalmente a uma anomalia de baixa resistividade, pelo fato de conter muita água, preenchimento por material argiloso saturado, ou ambos (KELLY \& MARES 1993). GALLAS (2003) sugere que, na ausência de aerolevantamentos ou informações geológicas, as seções geofísicas devem ser posicionadas de acordo com uma malha quadrada ou de forma triangular, pois isto possibilita um efetivo recobrimento das estruturas existentes. O método de potencial espontâneo (SP), também elétrico, mede a diferença de potencial natural entre quaisquer dois pontos do terreno; o fluxo de água subterrânea ao longo de zonas de falha pode ser obtido pelo método SP (KELLY \& MARES 1993).

O método áudio-magneto-telúrico (geofísica de superfície) detecta estruturas com fortes anisotropias, tais como diques de basaltos compactos contidos em basaltos fraturados, ou fraturas mais abertas com rápida percolação de água subterrânea contidas em rochas pouco permeáveis. A profundidade de investigação é bastante variável, indo desde 50 até 400m (MEJU et al. 1999, DUSSEL et al. 2000, TROEGER et al. 2001), sendo esta uma das vantagens desse método em relação aos caminhamentos elétricos.

No que diz respeito à geofísica de poço, os métodos podem ser divididos em convencionais (caliper ou calibre, gama, temperatura da água, condutividade da água e indução eletromagnética) e avançados (perfilagens óptica, acústica, de velocidade de fluxo, entre outras) (JOHNSON et al. 2002).

A perfilagem de calibre gera um registro contínuo do diâmetro do poço. Aumentos no diâmetro podem ser relacionados tanto à presença de fraturas como a mudanças litológicas, ou ainda, a aspectos da construção dos poços. Os perfis gama natural e gama-gama servem normalmente como indicadores de litologia, mas também podem detectar fraturas abertas ou fechadas. Alta atividade gama é tipicamente associada à presença de unidades sedimentares de granulação fina, que tendem a acumular radioisótopos por meio de processos de adsorção ou troca iônica (MORIN et al. 2000). As perfilagens de temperatura e condutividade da água indicam entradas ou saídas de água que se relacionam à presença de fraturas hidraulicamente mais ativas. A de indução eletromagnética registra a condutividade elétrica das rochas, bem como dos fluidos contidos nelas, que são imediatamente adjacentes à parede do poço. Mudanças na condutividade são causadas por variações na porosidade, diâmetro do poço, composição da água contida nas rochas e mineralogia (minerais metálicos).

As perfilagens óptica e acústica fornecem imagens planas da parede do poço, orientadas com relação ao norte, onde podem ser visualizadas fraturas, que aparecem como uma curva senóide, a partir da qual é possível caracterizar a direção, bem como a magnitude e o sentido do mergulho (ZEMANEK et al. 1970, JOUANNA 1993, JOHNSON et al. 2002). Na perfilagem óptica é possível visualizar aspectos estruturais e texturais da rocha, enquanto que na acústica aparecem apenas as principais feições estruturais; neste caso a correlação da textura da imagem com o tipo de rocha não é tão direta. A primeira deve ser realizada em água límpida, enquanto que a segunda também pode ser conduzida em água turva. A perfilagem de velocidade, realizada com uma ferramenta denominada flowmeter, mede a direção e a velocidade de fluxo no poço. Utilizada junto com outras perfilagens, tais como de temperatura, calibre, óptica ou acústica, permitem indicar a localização de fraturas individuais ou grupos de fraturas mais condutoras (BARTON et al. 1995, MORIN et al. 1997, 2000, JOHNSON et al. 2002, FERNANDES et al. 2008b).

\section{ANÁLISE DE DADOS DE POÇOS PARA O ENTENDIMENTO DO COMPORTAMENTO DOS AQÜÍFEROS FRATURADOS}

Os dados de poços utilizados para o entendimento do comportamento de aqüíferos fraturados são aqueles coletados em investigações de detalhe, com a utilização de perfilagens e ensaios hidráulicos em poços, até os dados de produção (vazão e capacidade específica). A análise de correlação entre os dados de produção e os fatores que supostamente influenciam o fluxo tem sido realizada com o objetivo de reduzir os insucessos na locação de poços para captação de água em aqüíferos fraturados.

Os trabalhos encontrados na literatura que versam sobre este tema, avaliam a influência de fatores tais como: tectônica, proximidade a lineamentos, natureza e espessura do manto inconsolidado, litologia, compartimento topográfico, profundi- 
dade das entradas de água no poço. Os resultados destes trabalhos podem trazer informações importantes para o entendimento preliminar das propriedades hidráulicas dos aqǘferos fraturados. Este tipo de avaliação é relevante, pois a construção de poços exclusivamente para pesquisar tais aqüíferos torna os estudos bastante onerosos e a extrapolação dos seus resultados enfrenta dificuldades devido ao fato, a princípio, de serem locais. Assim, a utilização criteriosa de dados de poços pré-existentes sempre constituirá um componente importante para a análise de aqüíferos, sejam eles fraturados ou granulares. No entanto, a verificação da consistência e a comparação de resultados obtidos em diferentes trabalhos muitas vezes não é possível devido à forma como os dados são apresentados. Assim, a apresentação de medianas é mais adequada que de médias, principalmente quando acompanhadas de desvios padrões e quartis. No entanto, gráficos que ilustram todos os dados de produção - como, por exemplo, os de distribuição acumulada, com escala logarítmica para o parâmetro de produção (capacidade específica ou vazão) - são os que possibilitam comparações entre os fatores analisados e entre regiões diferentes.

A seguir é apresentada uma análise, baseada em estudos locais e regionais, dos fatores considerados como influentes sobre a circulação de água em meios fraturados. A tabela 1 traz uma síntese de tal análise e a tabela 2 indica os métodos de identificação dos caminhos preferenciais de fluxo em aqüíferos fraturados recomendados neste trabalho.

\subsection{Tectônica}

O papel principal da tectônica no fluxo da água subterrânea é exercer forte controle sobre a abertura das fraturas, bem como sobre direções e densidades de fraturas, e, consequentemente, sobre conectividade e armazenamento do aqüífero. Exemplos deste controle têm sido recentemente bem documentados por vários estudos em diversas situações geológicas (BANKS et al. 1994, BARTON et al. 1995, FERRIL et al. 1999, FERNAN-

TABELA 1 - Fatores que controlam o fluxo de água subterrânea: seu alcance e suas limitações.

\begin{tabular}{|c|c|c|}
\hline & Exerce controle sobre & Limitações \\
\hline \multirow[t]{2}{*}{ Tectônica } & $\begin{array}{l}\text { Direção das fraturas mais abertas, con- } \\
\text { trolando a direção da maior K e trans- } \\
\text { missividade. }\end{array}$ & $\begin{array}{l}\text { Muitas vezes não é disponível em trabalhos anterio- } \\
\text { res e a coleta e análise de dados estruturais pode ser } \\
\text { demorada e exige profissionais especializados. }\end{array}$ \\
\hline & $\begin{array}{l}\text { Densidade e direção dos grupos de fra- } \\
\text { turas controlando a conectividade e ar- } \\
\text { mazenamento da rede de fraturas. }\end{array}$ & \\
\hline Lineamentos & $\begin{array}{l}\text { Locação do poço próxima a zona(s) de } \\
\text { fraturas ou sob a influência de zona(s) } \\
\text { de fraturas. }\end{array}$ & $\begin{array}{l}\text { Escalas pequenas }(<1: 25.000) \text { não permitem corre- } \\
\text { lação com fraturas que atravessam os poços. } \\
\text { Lineamentos de áreas de relevo suave muitas vezes } \\
\text { podem não ser correlacionáveis a estruturas de sub- } \\
\text { superfície e não apresentam correlação com a densi- } \\
\text { dade de tais estruturas. }\end{array}$ \\
\hline $\begin{array}{l}\text { Manto inconso- } \\
\text { lidado }\end{array}$ & Recarga de aqüíferos. & $\begin{array}{l}\text { É descontínuo e de difícil mapeamento. Análises } \\
\text { regionais não permitem observação de correlação } \\
\text { entre espessura de manto inconsolidado e } \mathrm{Q} / \mathrm{s} \text {. }\end{array}$ \\
\hline Litologia & $\begin{array}{l}\text { Presença de descontinuidades prévias } \\
\text { (acamamento, contatos, bandamento) e } \\
\text { modo de propagação de fraturas. }\end{array}$ & $\begin{array}{l}\mathrm{O} \text { controle exercido pela litologia é subordinado à } \\
\text { tectônica no que diz respeito às fraturas de maior K. }\end{array}$ \\
\hline $\begin{array}{l}\text { Compartimento } \\
\text { topográfico }\end{array}$ & $\begin{array}{l}\text { Saturação de: fraturas superficiais (ho- } \\
\text { rizontais e verticais) e manto inconso- } \\
\text { lidado, pois nos vales o nível d'água é } \\
\text { mais próximo à superfície. }\end{array}$ & $\begin{array}{l}\text { Os vales devem ser associados a lineamentos, ou } \\
\text { seja, o maior controle é exercido por estes últimos. }\end{array}$ \\
\hline Profundidade & $\begin{array}{l}\text { Transmissividade de fraturas verticais } \\
\text { diminui muito a partir de } 300 \mathrm{~m} \text { de pro- } \\
\text { fundidade e das horizontais, a partir de } \\
30 \mathrm{~m} \text {. }\end{array}$ & $\begin{array}{l}\text { A análise deste parâmetro é fortemente influencia- } \\
\text { do pelo fato de poços serem aprofundados somente } \\
\text { quando produções adequadas não são obtidas com } \\
\text { poços mais rasos. }\end{array}$ \\
\hline
\end{tabular}


TABELA 2 - Método proposto para identificação de situações mais propícias para: locação de poços e de determinação de caminhos preferenciais de circulação de água subterrânea.

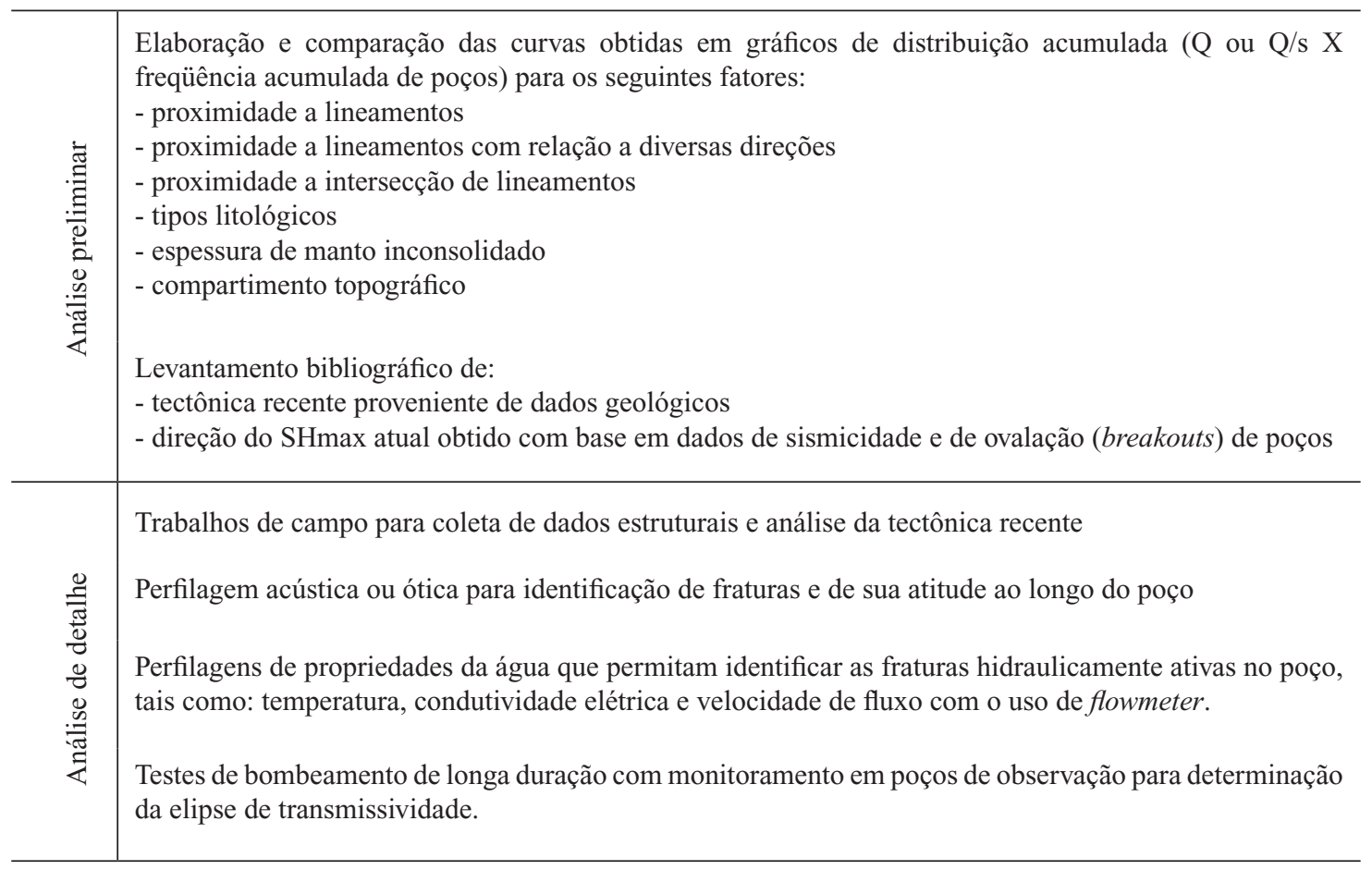

DES \& RUDOLPH 2001a e b, MORIN \& SAVAGE 2003, MORIN et al. 2006).

BANKS et al. (1994) apresentam alguns estudos de caso onde foi percebida a relação entre o esforço tectônico (atual in situ e paleo-esforço) e produtividade de poços e fraturas de maior abertura hidráulica.

BARTON et al. (1995) observaram que 70 a $80 \%$ das fraturas identificadas como condutoras estavam em orientação ótima com relação ao campo de esforços in situ. As fraturas condutoras são paralelas ao SHmax (esforço horizontal máximo) do local (fraturas do tipo I) ou fazem ângulo agudo de até $30-40^{\circ}$ com este esforço (fraturas do tipo II), apresentando mergulhos desde elevados a médios. Valores de transmissividade deduzida a partir de dados de testes de bombeamento de longa duração também indicam que falhas e fraturas idealmente orientadas para o deslizamento e para a dilatação no campo de esforços atual são mais permeáveis (FERRIL et al. 1999).

MORIN \& SAVAGE (2003) mostram que fraturas pré-existentes subverticais de orientação paralela ao SHmax têm transmissividades significativamente maiores que as ortogonais. Os autores concluem que apesar dos diferentes contextos geológicos e tectônicos dos locais estudados, a relação entre esforços, fraturas e fluxo de água é comum e pode ser traçada com base em dados de perfilagem geofísica e pelo desenvolvimento complementar de modelos de esforços. Campo de esforços oriundo da somatória de efeitos da topografia e do contraste da relação de Poisson, entre tipos litológicos distintos e superpostos, resulta em esforço horizontal efetivo extensional para basaltos superpostos a arenitos (MORIN et al. 2006). Esforços induzidos por gravidade e tectônica sob um vale simétrico também são apontados por MORIN \& SAVAGE (2003) como responsáveis pelo aumento sistemático da conectividade e abertura de fraturas com a profundidade na situação de encostas em basaltos.

A influência da tectônica sobre a produção de poços também foi observada em FERNANDES (1997), FERNANDES \& RUDOLPH (2001 a, b) e FERNANDES et al. (2005). FERNANDES (1997) e FERNANDES \& RUDOLPH (2001a, b) mostram que poços situados em lineamentos paralelos a fraturas extensionais, geradas por dois eventos tectônicos quaternários, que atuaram em domínios tectônicos distintos na região de Campinas, são 
significativamente mais produtivos que os localizados próximos a lineamentos paralelos a fraturas de cisalhamento dos mesmos eventos (Figura 7).

FERNANDES et al. (2005) identificaram blocos geológicos que indicam a existência de regiões com potenciais distintos de produção para granitos e rochas metamórficas (não carbonáticas) de alto e baixo grau do Estado de São Paulo (Figura 8). Na escala de análise utilizada (1:1.000.000), os blocos geológicos revelaram-se bem mais influentes que a litologia, densidade e intersecção de lineamentos e espessura de manto inconsolidado. Tais blocos são balizados por limites entre terrenos pré-cambrianos (zonas de cisalhamento) ou por lineamentos que representam estruturas rúpteis significativas, algumas ativas durante o Cenozóico. Tais limites ainda não são bem compreendidos, no entanto, sugerem que os blocos correspondam a domínios estruturais distintos com diversas potencialidades hidrogeológicas. A tectônica recente, que, por vezes, reativou estruturas antigas, como zonas de cisalhamento ativas no limite Pré-Cambriano/Fanerozóico, teve papel fundamental na delimitação desses blocos.

GUDMUNDSSON et al. (2003) consideram que falhas ou fraturas de cisalhamento também são importantes condutos de água pelo fato de evoluírem a partir de fraturas menores, comumente grupos de fraturas extensionais. A

(A) 286 288 290

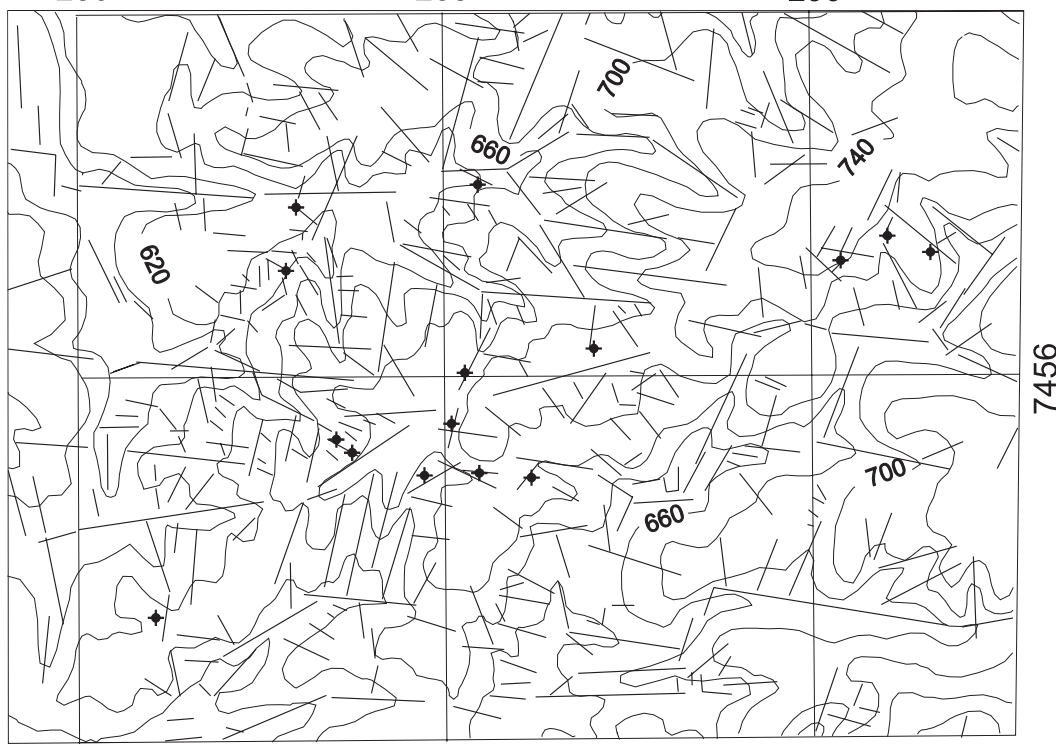

LEGENDA

_ Lineamento

- Poço

+7456 Coordenada UTM

Curvas de nível da superfície do terreno, em metros sobre o nível do mar.

Equidistância de 20 m.

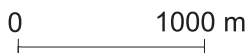

(B)

Comprimento acumulado de lineamentos

(C)

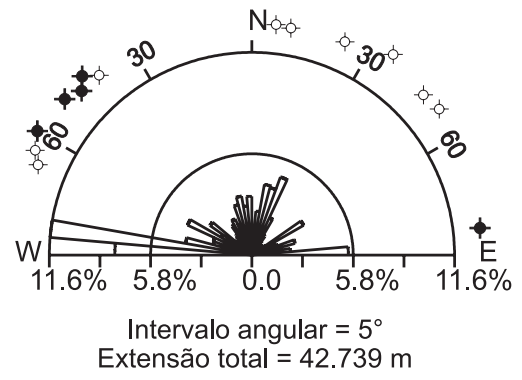

Poço com capacidade específica igual ou maior que $0,5 \mathrm{~m}^{3} / \mathrm{h} / \mathrm{m}$

Poço com capacidade específica menor que $0,5 \mathrm{~m}^{3} / \mathrm{h} / \mathrm{m}$

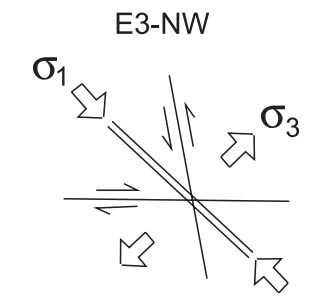

FIGURA 7 - (A) Mapa topográfico com os lineamentos traçados em fotos aéreas em escalas 1:25.000 e 1:60.000 e a localização de poços. (B) Rosácea com os trends de lineamentos mostrando a variação da capacidade específica dos poços em função da orientação dos lineamentos. (C) Orientação esquemática das fraturas de cisalhamento e extensão geradas pelo evento E3-NW de idade quaternária. Os poços mais produtivos estão próximos a lineamentos paralelos às fraturas extensionais (direção $\mathrm{NW}$ ) que são perpendiculares a $\sigma 3$ do evento E3-NW (modificado de FERNANDES 1997, FERNANDES \& RUDOLPH 2001a, b). 

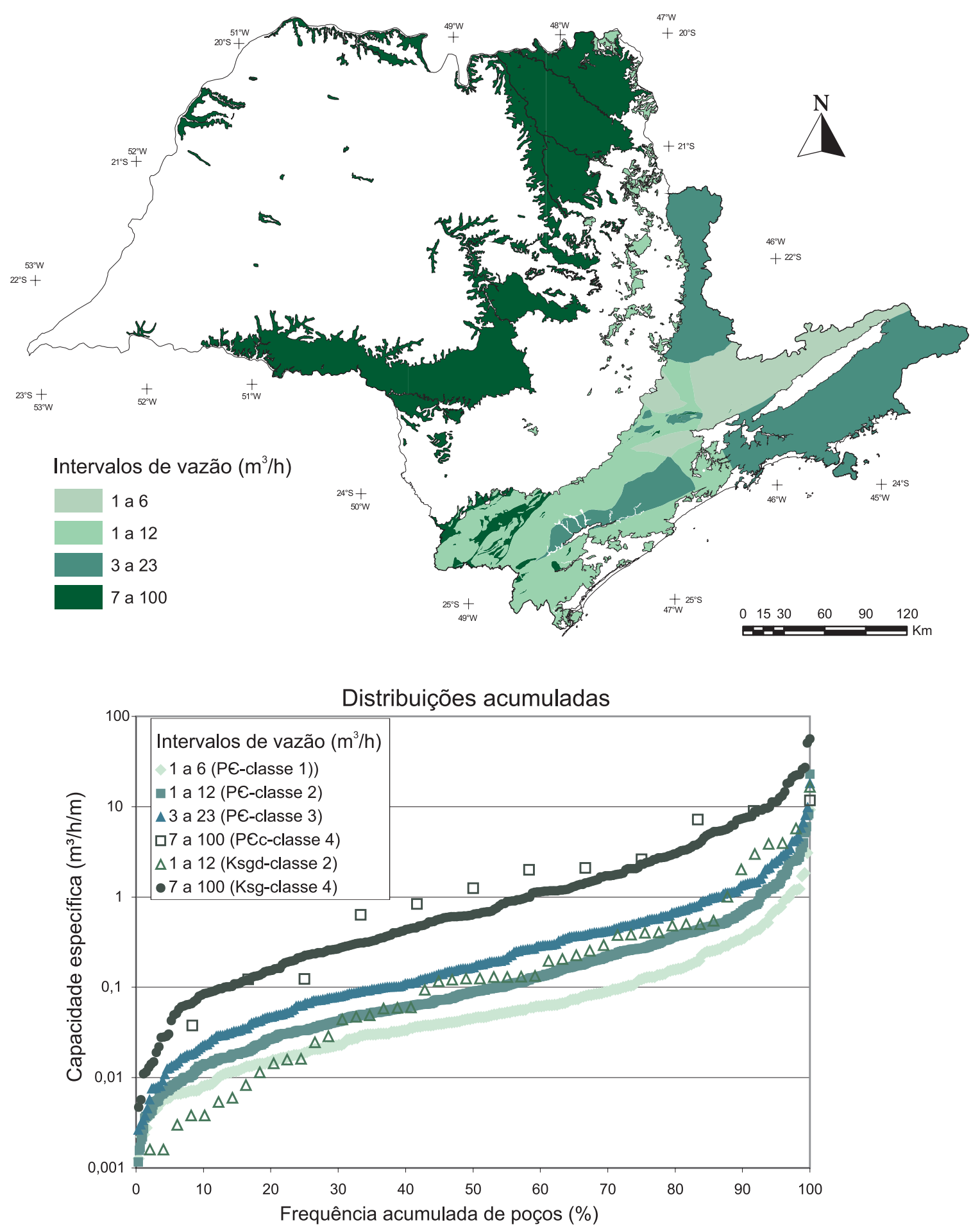

FIGURA 8 - Regiões com potenciais distintos de produção e respectivas curvas de distribuição acumulada para as rochas pré-cambrianas constituídas por granitos e rochas metamórficas (não carbonáticas) de alto e baixo grau do Estado de São Paulo (FERNANDES et al. 2005). 
permeabilidade destas estruturas muda muito ao longo da deformação (UNESCO 1984) (Figura 9). TIRÉN (1991) conclui que as zonas de fraturas mais favoráveis para conduzir água são aquelas que sofreram longa e complexa história tectônica, com a atuação de deformação dúctil e rúptil. Deslizamentos repetidos em falhas podem levar ao desenvolvimento de duas unidades hidromecânicas principais, denominadas de: (1) fault-damage zone e (2) fault core (EVANS et al. 1997). A primeira apresenta permeabilidades 3 a 4 ordens de grandeza superiores à segunda, sendo que o protolito, ou rocha não deformada apresenta permeabilidades intermediárias. Assim, zonas de falha com damage zones bem desenvolvidas podem levar a um aumento do fluxo de fluidos ao longo de uma região tabular e pouco espessa, ao passo que o fault core impede o fluxo através da falha, ou seja, constitui barreira hidráulica.

A reativação de fraturas pré-existentes dá-se em duas etapas sucessivas: deformação elástica, na qual a dilatação é mínima, e deformação por cisalhamento, acompanhada por dilatação significativa (LONG 1996), que causa aumento da transmissividade (T) (LAMONTAGNE 2001) (Figura 10).

Ainda em relação ao papel das falhas na circulação de água subterrânea, MAZUREK et al. (1998) chegaram a um modelo mecânico conceitual no qual as falhas são constituídas por segmentos mais longos - menos transmissivos - , onde dominou cisalhamento, e segmentos mais curtos e transmissivos onde dominou dilatação (dilational jogs ou splay cracks). Isto foi constatado pela falta de correlação das entradas de água com grupos específicos de fraturas (classificadas quanto a direção, litologia atravessada, espessura, entre outros); assim, deduziram que todas as falhas são provavelmente igualmente transmissivas, mas apresentam heterogeneidade interna que leva a fluxo acanalado e, portanto, a variação de transmissividade $(\mathrm{T})$ em seu interior. Foram investigadas profundidades de até $2000 \mathrm{~m}$ e constatou-se que a transmissividade diminui significativamente a profundidades maiores que $300 \mathrm{~m}$; no entanto, o tamanho e a frequência de falhas não variam com a profundidade. Evidências hidroquímicas mostram que existem redes de fraturas conectadas (acima do limiar de percolação) até a profundidade de $400 \mathrm{~m}$.

\subsection{Lineamentos}

A análise da produção de poços em função de sua localização com relação a diversas características de lineamentos (proximidade, direção, densidade e intersecção) é bastante comum para o Estado de São Paulo (DAEE 1979, 1981, 1982; SILVA 1984; COSTA 1986; BERTACHINI 1987; MENEGASSE 1991; DEL REY 1991; SIDLE \& LEE 1995; FERNANDES 1997; FERNANDES \& RUDOLPH 2001a, b; PERROTTA \& SALVADOR 2002; TAKAHASHI et al. 2003; MADRUCCI 2004; FERNANDES et al. 2005). A intersecção de lineamentos está atrelada à questão da conectivi-

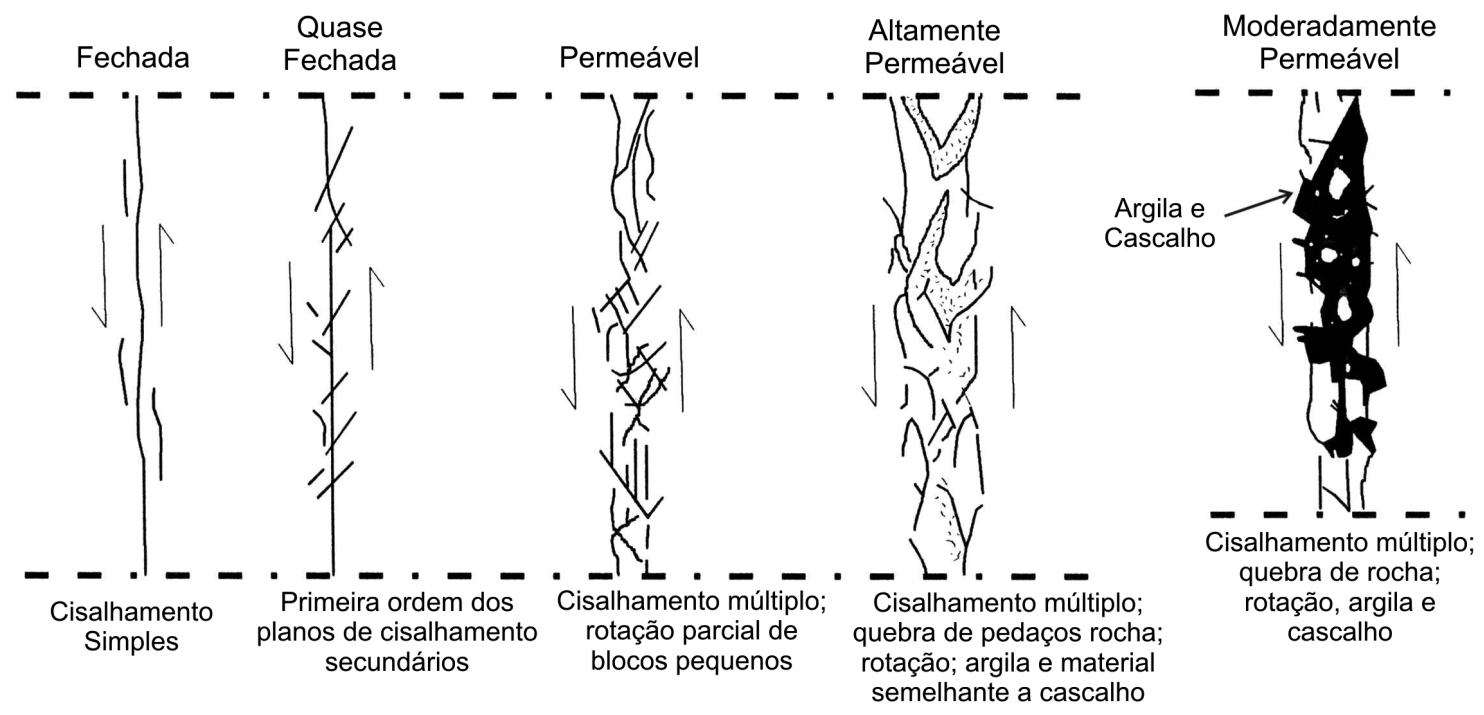

FIGURA 9 - Variação da permeabilidade em falhas que se encontram em vários estágios de desenvolvimento, do menos (esquerda) para o mais (direita) desenvolvido (modificado de UNESCO 1984). 


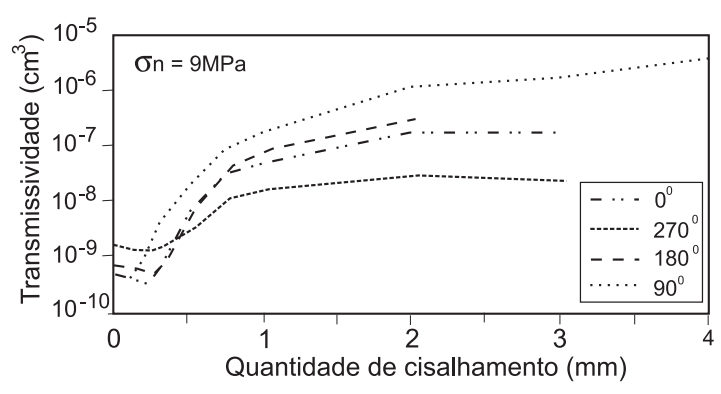

FIGURA 10 - Transmissividade de uma fratura em função do cisalhamento e da direção e sentido em que este ocorre. Foram testadas 2 direções e 4 sentidos distintos $\left(90^{\circ}, 180^{\circ}, 0^{\circ}\right.$ e $\left.270^{\circ}\right)$, tendo como referência as rugosidades da fratura (Adaptado de LAMONTAGNE 2001).

dade de fraturas e, de fato, está associada a maiores produções de poços (Figura 11). No entanto, a análise de lineamentos não permite caracterizar as zonas de fraturas em relação a uma série de fatores de grande importância para a circulação de água subterrânea em meios fraturados, como largura da zona fraturada, abertura das fraturas e continuidade lateral e vertical, constituindo uma grande limitação do método.

MEISER \& EARL HYDROGEOLOGISTS (1982) consideram que: (1) as feições associadas a fraturas com maior capacidade de transmitir água subterrânea seriam estreitas e frequentemente independentes de trends estruturais regionais e (2) o melhor material de análise seriam fotos preto e branco na escala 1:20.000, de várias épocas, uma

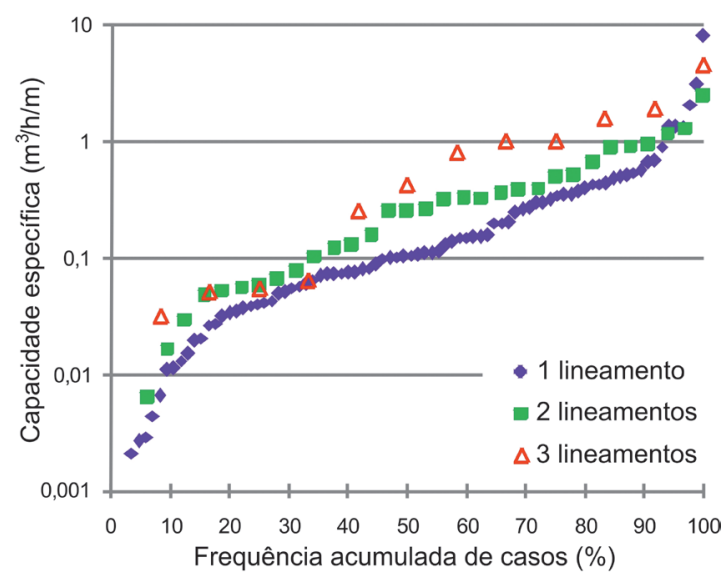

FIGURA 11 - Influência da intersecção de lineamentos na produção de poços (FERNANDES 1997, FERNANDES \& RUDOLPH 2001). vez que a ocupação tende a esconder as feições naturais mais sutis.

GUSTAFSSON (1994) utilizou o traçado de lineamentos em imagens Spot multi-espectrais (XS) e pancromática (P) com resolução de 20 e $10 \mathrm{~m}$, respectivamente, em região semi-árida. A disponibilidade de registros para estações diferentes permitiu identificar lineamentos que suportam vegetação bastante saudável durante a estação seca, provavelmente associados a zonas de fratura com água.

MABEE et al. (1994) propõem um método para coleta de lineamentos onde seriam eliminados aqueles que: (1) não tivessem sido identificados pelos vários observadores envolvidos e (2) que não coincidissem, considerando o posicionamento geográfico, com as direções das fraturas levantadas em trabalhos de campo. Com isso o número de lineamentos interpretados foi reduzido de 6500 para 217. Poços locados a uma distância menor que $30 \mathrm{~m}$ dos lineamentos, que obedecem a estes critérios, têm transmissividade, em geral, maior que aqueles locados nos demais lineamentos. Este método, no entanto, deve ser aplicado em locais onde exposições de rochas sejam comuns.

Vários autores (SILVA 1984, COSTA 1986, BERTACHINI, 1987 e MENEGASSE 1991) analisaram o papel da orientação de lineamentos, cuja natureza (p. ex., fraturas de cisalhamento e fraturas extensionais) foi interpretada com base na evolução de estruturas antigas (Pré-cambriano a início do Paleozóico), que provavelmente não exercem nenhum controle sobre as estruturas extensionais atuais.

MEYJERINK et al. (2007) citam trabalhos que relacionam a produção de poços com a direção de lineamentos e verificaram que os resultados são diversificados, havendo casos onde fica clara a associação de poços mais produtivos com determinadas direções de lineamentos e outros onde este tipo de associação não é claro.

Com o objetivo de avaliar o papel da densidade de lineamentos (para todas as direções, direções específicas e combinação de direções) e da interseccção de lineamentos, nas várias combinações possíveis, FERNANDES et al. (2005) elaboraram um mapa de lineamentos em escala 1:500.000 para a área aflorante dos aqüíferos Serra Geral e précambrianos do Estado de São Paulo, sobre imagens LANDSAT TM-5, cenas 219-76, 219-77, 218-76, 219-75 e 220-77 (aqüíferos pré-cambrianos) e modelo digital de elevação (MDE) produzido na Missão Topográfica por Radar Interferométrico (Shuttle Radar Topographic Mission - SRTM). 
Correlações positivas com a capacidade específica de poços foram obtidas apenas para a densidade de lineamentos EW e para a densidade de intersecções entre as direções EW e NS. Este resultado, no entanto, é conclusivo apenas para a região localizada entre São Paulo e Campinas, onde existe uma maior densidade de poços. Para as demais áreas os dados de poços são muito esparsos e os resultados não foram conclusivos. Para a área de ocorrência de basaltos foi verificada ausência de correlação entre produção de poços e densidades e intersecções de lineamentos. Isto deve-se, provavelmente, ao fato das feições de maior permeabilidade nos basaltos corresponderem a fraturas sub-horizontais e contatos entre derrames (SINELLI 1971, REBOUÇAS 1978, QUADROS et al. 1991, TRESSOLDI 1991, FERNANDES et al. 2006, 2008b), que, no entanto, não são identificáveis em imagens de sensores remotos. Por outro lado, o DAEE (1979), no estudo das regiões administrativas 10 e 11, em escala maior $(1: 250.000)$, concluiu que os poços que exploram os basaltos próximos a lineamentos de drenagem são 10 vezes mais produtivos do que aqueles mais distantes destas feições. Disto pode ser concluído que a influência de fraturas verticais em basaltos pode ser negligenciável em algumas regiões, mas significativa em outras.

Os resultados de análise da produção de poços com relação à proximidade ou direção de lineamentos deve ter interpretações distintas dependendo da escala em que os lineamentos foram traçados. Quando são utilizadas fotos aéreas de grandes escalas (1:25.000 ou maiores) pode-se dizer que é provável que o poço esteja interceptando fratura de mesma direção que o lineamento interpretado. No entanto, para escalas menores (fotos 1:60.000 ou imagens 1:100.000) não existe resolução suficiente para se avaliar tal aspecto, sendo possível apenas afirmar que o poço pode estar na zona de influência daquela feição; porém, o poço em si pode estar seccionando feições de diferentes direções que não chegaram a ser traçadas como lineamentos. Assim, quando escalas pequenas são utilizadas, a atribuição de características hidráulicas específicas às direções de lineamentos interpretados incorre em graus de incerteza extremamente elevados e este tipo de atribuição deve ser evitado, como sugerido por FERNANDES (2006). Lineamentos interpretados em áreas de relevo suave muitas vezes podem não ser correlacionáveis a estruturas de subsuperfície e não apresentam correlação com a densidade de tais estruturas (FERNANDES \& RUDOLPH 2001).

\subsection{Manto inconsolidado}

Existe muita dificuldade em avaliar o fluxo de água através do manto inconsolidado devido à sua grande heterogeneidade. A camada de materiais inconsolidados exerce papel importante na recarga de água do aquífero de rocha sã fraturada. A recarga, em regiões de aquíferos fraturados, é de origem local, uma vez que as camadas de alteração tendem a ser descontínuas, lateral e verticalmente (UNESCO 1984).

As maiores permeabilidades do manto inconsolidado estão associadas à base do saprolito (horizonte $\mathrm{C}$ ) e à parte superior da rocha alterada, caracterizada por um misto de rocha fresca e de saprolito, algumas vezes denominada de saprock (BALL \& HERBERT 1993, CHILTON \& FOSTER 1995). A condutividade hidráulica do horizonte $\mathrm{C}$ pode chegar à ordem de $10^{-2}$ e $10^{-3} \mathrm{~cm} / \mathrm{s}$, enquanto o horizonte $B$ apresenta valores da ordem de $10^{-5}$ a $10^{-8} \mathrm{~cm} / \mathrm{s}$ (UNESCO 1984).

Segundo a UNESCO (1984), as produções dos poços com 10 a $30 \mathrm{~m}$ de profundidade, em áreas onde o manto de alteração varia de 10 a $20 \mathrm{~m}$ de espessura, na região de clima úmido do Brasil, variam de 0,5 a $15 \mathrm{~m}^{3} / \mathrm{h}$ (vazão) ou 0,2 a 4 m³/h/m (capacidade específica, Q/s). Apesar dos valores de $\mathrm{Q} / \mathrm{s}$ relativamente elevados, estes aqüíferos são muito vulneráveis e ainda é necessário avaliar a manutenção das produções para maiores períodos de tempo.

Uma grande quantidade de dados obtidos na África tropical mostra que não existe correlação entre a espessura do manto inconsolidado e a capacidade específica de poços (CHILTON \& FOSTER 1995) (Figura 12).

Uma análise dos poços em rochas pré-cambrianas do Estado de São Paulo mostrou que a espessura de manto inconsolidado, nesta escala de análise, não exerce influência sobre a variação da produção de poços (FERNANDES et al. 2005). FERNANDES (1997) mostra ainda que as maiores produções de poços profundos sempre estão vinculadas a lineamentos, mesmo quando os poços exploram o manto inconsolidado saturado (Figura 13).

\subsection{Litologia}

Xistos, filitos, rochas básicas intrusivas (gabros e dioritos), anfibolitos e milonitos, associados a grandes zonas de cisalhamento, são apontados como de menor potencial de produção quando 


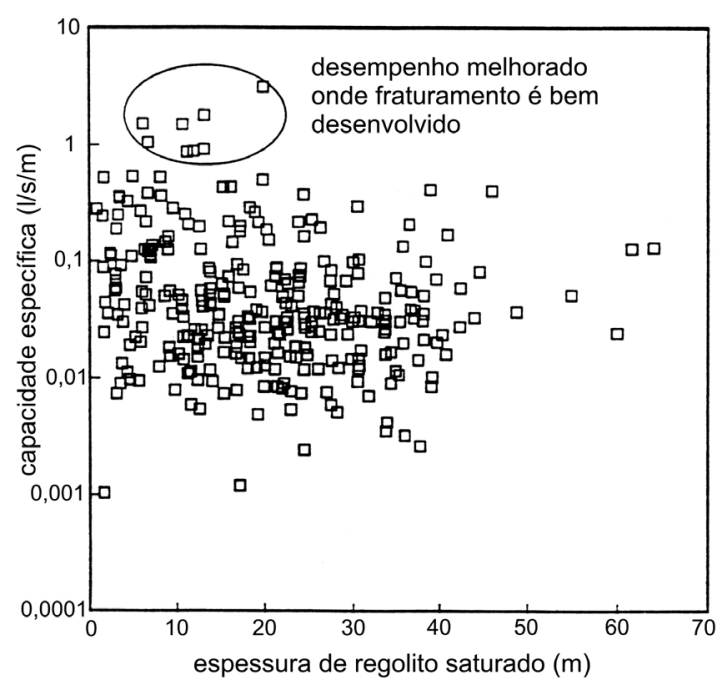

FIGURA 12 - Relação entre capacidade específica e espessura de regolito saturado para poços de pequeno diâmetro em rochas intemperizadas de aquíferos do Malawi (Adaptado de CHILTON \& FOSTER 1995).

comparados a granitos, granodioritos, aplitos, quartzo-pórfiros e pegmatitos (UNESCO 1984). Gnaisses tenderiam a produzir vazões semelhantes (ligeiramente menores) às de migmatitos e granitos (GUSTAFSSON \& KRÁSNÝ 1994, BANKS et al. 1994). No entanto, FERNANDES et al. (2005), avaliando as rochas pré-cambrianas do Estado do São Paulo, obtiveram resultado diverso, em que gnaisses mostraram-se mais produtivos que granitos. Por outro lado, rochas metamórficas de baixo grau apresentam maior variação de capacidade específica, com as menores produções assemelhando-se às dos granitos, e as maiores, às dos gnaisses (Figura 14).

Observa-se que as diferenças de capacidade específica média entre os vários tipos litológicos estão tipicamente ao redor de uma ordem de grandeza. Por outro lado, a variação dentro de um mesmo tipo litológico pode ser de três ordens de grandeza, ou sete a oito ordens em termos de permeabilidade, concluindo-se que outros fatores, em geral, são mais importantes (BANKS et al. 1994). KNOPMAN \& HOLLYDAY (1993) chegaram à conclusão que variações litológicas, considerando calcários e dolomitos, siliciclásticas e rochas ígneas e metamórficas, explicam somente $12 \%$ das variações de produção.

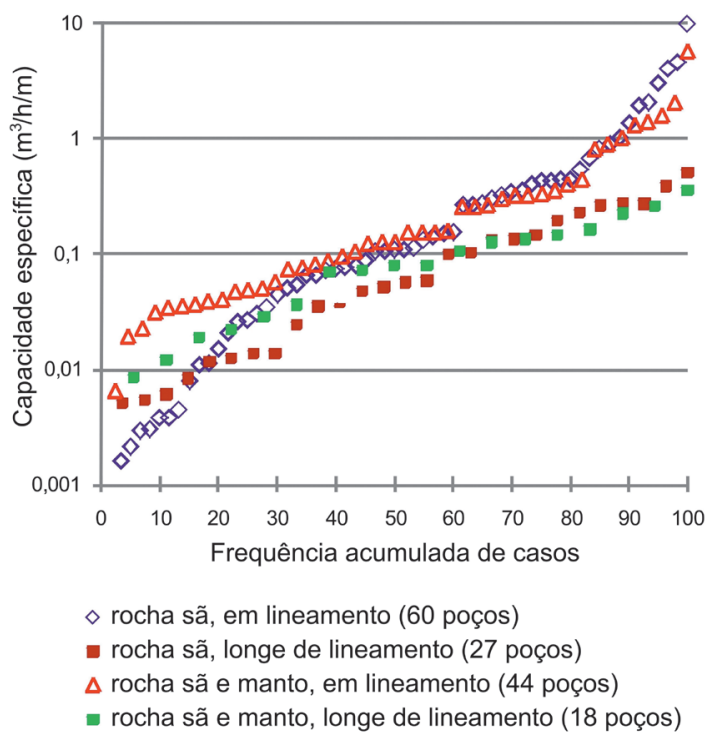

FIGURA 13 - Gráfico de distribuição acumulada que relaciona manto inconsolidado e lineamentos com produção de poços (FERNANDES 1997, FERNANDES \& RUDOLPH 2001)

Contatos de pequenos corpos intrusivos com grandes diferenças texturais e/ou mineralógicas com relação às encaixantes, tais como diques de doleritos (SAMI 1996) e diques de pegmatitos (FLORQUIST et al. 1972) mostram-se produtivos provavelmente pelo fato dos limites com as encaixantes serem frequentemente muito fraturados (GUSTAFSSON 1994).

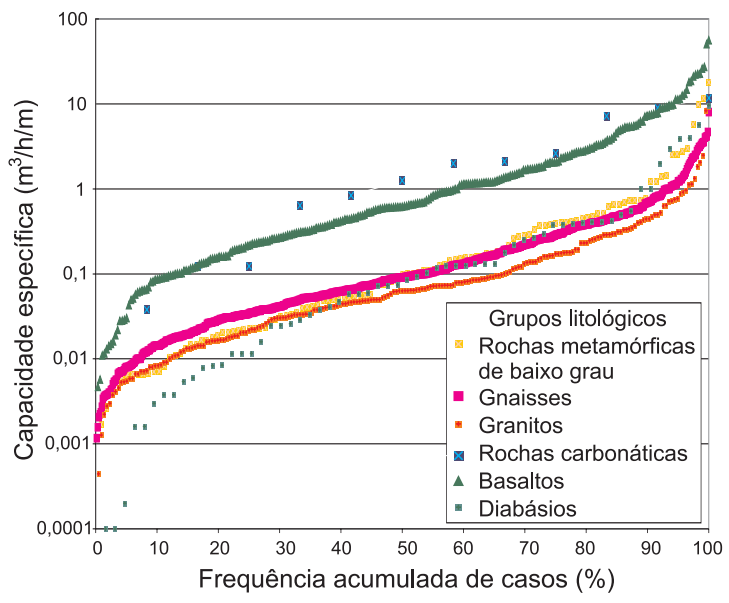

FIGURA 14 - Distribuição acumulada dos valores de capacidade específica dos poços em rochas cristalinas do Estado de São Paulo (FERNANDES et al. 2005). 
Acamamentos e contatos litológicos também podem constituir os principais caminhos para o fluxo (LACHMAR 1994, MORIN \& SAVAGE 2003), no entanto, são mais susceptíveis à pressão litostática e podem se fechar a pouca profundidade (MORIN et al. 1997, MORIN \& SAVAGE 2003).

\subsection{Compartimento topográfico}

Algumas análises tem verificado que poços perfurados na base de vales podem chegar a ser oito vezes mais produtivos do que os de terrenos de topo (PARIZEK \& SIDDIQUI 1969, FERNANDES 1997). Para FERNANDES (2006) o melhor desempenho dos vales deve ser explicado pela associação de duas características: (1) nível d'água mais raso e (2) maior densidade de fraturas, característica que ocorre mais próximo à superfície. Devido a estas condições, poderá haver, nos vales, um incremento no fluxo de água devido à maior quantidade de fraturas saturadas. Apesar disto, as variações dentro de um mesmo compartimento topográfico são muito acentuadas e bem maiores que de um compartimento para outro (HENRIKSEN 1996, YIN \& BROOK 1996, KNOPMAN \& HOLLYDAY 1993, FERNANDES 1997, FERNANDES \& RUDOLPH 2001) (Figura 15). Quanto maior a quantidade de subdivisões de relevo utilizadas, menos significativas são as diferenças, do ponto de vista estatístico (YIN \& BROOK 1996). De um modo geral, as variações são significativas quando se compara o setor de vales/drenagens mais produtivo - com os compartimentos de topo e encosta. KNOPMAN \& HOLLYDAY (1993) concluem que, para todos os tipos litológicos avaliados

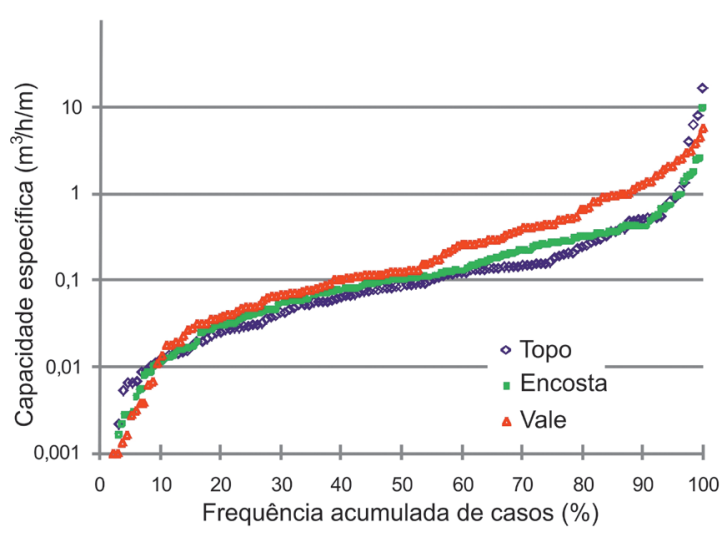

FIGURA 15 - Distribuições acumuladas relacionando capacidade específica de poços com diferentes compartimentos topográficos (FERNANDES 1997). pelos autores (calcários, dolomitos, siliciclásticas e rochas ígneas e metamórficas), o compartimento topográfico explicaria somente $7 \%$ das variações na produção.

\subsection{Profundidade das entradas de água}

Dentre os aspectos construtivos dos poços em aquíferos fraturados, um dos mais debatidos diz respeito à profundidade que um poço deve ser perfurado para se obter a melhor relação custo/benefício.

Estudos de injeção de água em fraturas indicam que, com o aumento da profundidade, o número de fraturas diminui e, devido às maiores pressões litostáticas, as suas aberturas tornam-se menores (DAVIS \& TURK 1963, LOISELLE \& EVANS 1995). BERTACHINI (1987) descreve dois intervalos de ocorrência mais freqüentes de entradas de água: de 60 a $81 \mathrm{~m}$, associadas aos poços mais produtivos, e de 102 a 144m; entradas de água ocorrem até $270 \mathrm{~m}$. CAVALCANTE (1990) observou que para $85,7 \%$ dos poços as entradas de água ocorrem até $154 \mathrm{~m}$. No Grupo São Roque, algumas entradas correspondem a contatos litológicos (MENEGASSE 1991). Em algumas regiões dos estados do Rio Grande do Norte e Paraíba, 55\% das entradas ocorrem até $20 \mathrm{~m}$ de profundidade, $35 \%$, de 20 a $40 \mathrm{~m}$, e $7 \%$, para profundidades maiores que $40 \mathrm{~m}$ (COSTA 1986). Estes dados apresentam um forte viés causado pelo fato de somente serem aprofundados aqueles poços nos quais as vazões desejadas não foram obtidas em profundidades mais rasas, mas isto, ao contrário de ser causado pela ausência de fraturas transmissivas em profundidade, foi inicialmente devido à locação do poço em situação desfavorável.

MORIN \& SAVAGE (2003) mostram que a diminuição da abertura de fraturas com a profundidade é significativa para fraturas sub-horizontais, pois a transmissividade destas a partir de 10-25 m diminui muito. No entanto, para fraturas de alto mergulho, a transmissividade é independente da profundidade, mas é dependente da sua orientação em relação ao campo de esforços atual. Os mesmos autores identificaram uma zona de fratura de alto mergulho bastante produtiva a $250-300 \mathrm{~m}$ de profundidade em basaltos.

\section{CONCLUSÕES E RECOMENDAÇÕES}

Recomenda-se inicialmente que os dados resultantes de análises de produção de poços em relação aos diversos fatores sejam apresentados de for- 
ma adequada para que ocorra avanço consistente do conhecimento sobre este tema ainda tão pouco conhecido e complexo. Neste sentido, a apresentação de gráficos de distribuição acumulada, onde todos os dados podem ser visualizados, é extremamente importante para distinção entre populações de dados de comportamento diferente. O uso de medianas também é muito mais recomendável que o de médias pois estas são distorcidas por alguns poucos valores mais elevados. $\mathrm{O}$ uso da capacidade específica, para avaliação das produções, também parece mais adequado que o de vazão, pois apesar do primeiro não ser um parâmetro exclusivo do aqüífero, ainda apresenta melhor correlação com a transmissividade (DAEE 1982). Para a sua utilização é importante que os dados sejam bem selecionados para diminuir a influência de aspectos construtivos dos poços.

No que diz respeito aos estudos que se baseiam em produção de poços, os resultados apresentados na literatura são controversos para alguns dos fatores analisados. Conclui-se que não é possível fazer generalizações, pois a escala de análise e as características locais dos aqüíferos têm grande influência sobre seu comportamento. No entanto, verifica-se que a tectônica é o fator que influi mais fortemente na circulação de água em rochas cristalinas, pois gera caminhos de percolação e controla, de modo geral, suas principais características geométricas (abertura, direções, densidade e conectividade). Destas, a abertura é a característica que exerce o mais forte controle sobre a condutividade hidráulica de fraturas; assim, os processos que a determinam devem ser entendidos, bem como as feições que permitem identificá-la (estruturas plumosas, entre outras). As fraturas mais abertas são as extensionais, perpendiculares a $\sigma 3$, e propagamse pelo modo I. De acordo com a literatura, podem ser geradas segundo uma das três condições: (1) em ambientes de regime tectônico extensional, (2) pela concentração de esforços nas terminações de estruturas pré-existentes, mesmo sob regime de esforços compressivo, ou ainda, (3) pela atuação da pressão de fluidos. A pressão de fluidos pode gerar tanto fraturas do modo I, quando o círculo de Mohr intercepta a envoltória de tração, como dos modos II e III, quando o círculo intercepta a envoltória de cisalhamento. Em virtude da magnitude relativa dos esforços principais, pode ser gerado apenas um grupo de fraturas de mesma direção ou padrões de orientações aleatórias.

Apesar de existir consenso em relação à grande importância das fraturas extensionais, devido à sua provável maior abertura, o mesmo não ocorre em relação ao papel das falhas ou zonas de fraturas de cisalhamento, já que podem apresentar comportamentos ambíguos. Quando mais evoluídas, podem corresponder a zonas de intensa moagem e presença de material fino impermeável; quando menos evoluídas e orientadas em posição favorável à movimentação segundo o campo de esforços atual, podem apresentar zonas mais permeáveis, onde ocorre dilatação devido à provável presença de pequenas fraturas extensionais. Cisalhamentos pequenos (1 a $2 \mathrm{~mm}$ ) podem promover um aumento significativo da condutividade hidráulica de fraturas reativadas. A zona central de falhas bem desenvolvidas pode ser muito menos permeável que as faixas deformadas adjacentes, chegando a constituir barreiras hidráulicas. Há também evidências de que falhas apresentariam trechos mais longos, onde domina cisalhamento, e trechos mais curtos, onde domina tração, de menor e maior condutividade hidráulica, respectivamente, resultando em fluxo preferencial acanalado.

Alguns autores, ao empregarem métodos sofisticados de estudo que contemplam perfilagens de poços e testes de bombeamento de muito longa duração em redes de poços, mostram que as fraturas mais transmissivas são paralelas ao esforço máximo principal do campo de esforços atual, ou estão orientadas em posição ótima com relação a este campo, ou seja, podem sofrer tanto cisalhamento como extensão. Outros estudos, que aliam estudo detalhado da tectônica cenozóica com avaliação da produção de poços, sugerem que eventos quaternários (e não necessariamente com campo de esforços coincidente com o atual), também condicionam a orientação de zonas de fraturas mais transmissivas.

É importante enfatizar que a abertura das fraturas, parâmetro que mais influi sobre a permeabilidade de fraturas, é também um dos mais difíceis de se determinar, pois o que é observado em afloramentos dificilmente representa o que ocorre em profundidade. Além disto, aberturas muito pequenas, não observáveis a olho nu, tem influência significativa sobre a permeabilidade.

Ainda não existe conhecimento consolidado no país sobre a influência da tectônica no fluxo de água em aqüíferos fraturados, sendo necessário desenvolver pesquisas com perfilagens e testes hidráulicos para validação de resultados. A associação de diferentes tipos de perfilagens, cujo custo não é elevado, traz resultados muito significativos. Os resultados adquiridos em pesquisas que empre- 
gam tais métodos, em conjunto com o levantamento de fraturas e análise estrutural e tectônica, são de grande valor para fundamentar e direcionar locações de poços, ainda que não sejam conduzidos especificamente para este fim.

Em relação ao fator lineamentos, sua densidade não é necessariamente correlacionável à densidade de fraturas, pois sofre influência da morfologia do terreno e da presença de coberturas. Nota-se, de um modo geral, que a proximidade de lineamentos influencia positivamente a produção de poços. No entanto, se não forem efetuados estudos da evolução tectônica mais recente, junto com a interpretação de lineamentos, visando identificar direções estruturais de maior condutividade hidráulica, este método se mostra bastante limitado. Outro aspecto que pode limitar muito os resultados é a escala de interpretação das feições lineares. Somente escalas maiores ou iguais a 1:25.000 tem precisão suficiente para identificar os lineamentos que de fato estão mais próximos de cada poço, sendo possível, então, fazer inferências sobre as direções das estruturas mais favoráveis à circulação da água subterrânea. Escalas pequenas como de fotos 1:60.000 ou imagens 1:100.000 não permitem tal interpretação.

A influência do manto inconsolidado pode ser deduzida apenas a partir de estudos locais, devido ao caráter muito descontínuo da espessura e natureza destes materiais, ou a partir de dados de perfis construtivos e litológicos, muitas vezes não disponíveis nos cadastros de poços.

O fator litologia, quando se trata de rochas metamórficas de alto e médio grau (exceto rochas carbonáticas) e rochas granitóides, apresenta influência sobre a produção de poços, mas bem menos significativa que a dos domínios estruturais (comentados abaixo). Rochas metamórficas de baixo grau parecem apresentar um comportamento mais diversificado: meta-arenitos e quartzitos são mais favoráveis, enquanto que filitos, ardósias e xistos são menos, muito provavelmente devido ao comportamento mecânico (resistência ao cisalhamento e relação de Poisson), que podem controlar o modo de propagação das fraturas. Ainda nestas rochas, os contatos entre tipos litológicos também devem ser importantes para a circulação de água subterrânea, em virtude da criação de espaços gerados pelo comportamento mecânico distinto. Os basaltos podem ter produção bastante independente da presença de fraturas tectônicas, já que apresentam feições de resfriamento sub-horizontais abundantes e permeáveis que, no entanto, devem estar fechadas em maiores profundidades.
Com relação ao compartimento topográfico, os vales mostram melhor desempenho muito provavelmente por associarem um nível d'água mais raso à presença de maior densidade de estruturas próximas à superfície, ou seja, estas encontramse saturadas, condições que ocorrem com menor freqüência em topos e encostas. Além disso, estas estruturas, principalmente as sub-horizontais, devem apresentar maior abertura em condições rasas. A presença de maior espessura de coberturas sedimentares também favoreceria produção e armazenamento maiores em vales e, consequentemente, a manutenção de vazões por períodos de tempo mais prolongados.

É bastante comum a recomendação de que poços em terrenos cristalinos não devam ser profundos, uma vez que em maiores profundidades as fraturas estão fechadas. Um dos argumentos utilizados é de que existe correlação negativa entre profundidade e produção de poços. No entanto, este dado apresenta um forte viés originado pelo fato de que, na maior parte dos casos, os poços só são aprofundados em virtude de não terem alcançado as produções desejadas em menor profundidade. Isto provavelmente resulta de uma locação não adequada, e não pelo fato das fraturas, pelo menos as subverticais, estarem fechadas em profundidade; observa-se que pelo menos até a profundidade de 300 a $400 \mathrm{~m}$ tem sido identificadas redes de fraturas conectadas e fraturas com transmissividades significativas. Assim, mais importante que recomendar uma profundidade máxima para a perfuração de poços é identificar as feições responsáveis pela maior circulação e armazenamento de água em um dado aqüífero e, a partir daí, realizar locações mais adequadas.

\section{REFERÊNCIAS BIBLIOGRÁFICAS}

BALL, D.F. \& HERBERT, R. 1993. The use of collector wells within the regolith aquifer of Sri Lanka. Ground Water, 30(5): 683-689.

BANKS, D.; RHOR-TORP, E.; SKARPHAGEN, H. 1994. Groudwater resources in hard rock: experiences from the Hvaler study, Southeastern Norway. Applied Hydrogeology, 2(2): 33-42.

BARTON, C.A.; ZOBACK, M.D.; MOOS, D. 1995. Fluid flow along potentially active faults in crystalline rock. Geology, 23(8): 683-686.

BERTACHINI, A.C. 1987. Estudo das características hidrogeológicas dos terrenos cristalinos 
sob clima úmido, na região de Jundiaí. Instituto de Geociências, Universidade de São Paulo, São Paulo, Dissertação de Mestrado, $180 \mathrm{p}$.

BJORNBERG, A.J.S. \& KUTNER, A.S. 1983. Resumo das feições geológicas de interesse às fundações em rocha, em barragens da Bacia do Alto Paraná. In: ABMS/ABGE/CBMR, SIMPÓSIO SOBRE A GEOTECNIA DA BACIA DO ALTO PARANÁ, 1, São Paulo, Vol. 1A: 263-297.

BRIZ-KISHORE, BH. 1993. Assessment of yield characteristics of granitic aquifers in South India. Ground Water, 31(6):921-928.

CAVALCANTE, I.N. 1990. Estudo hidrogeológico de terreno cristalino com manto de intemperismo: área piloto de Atibaia (SP). Instituto de Geociências, Universidade de São Paulo, São Paulo, Dissertação de Mestrado, $123 \mathrm{p}$.

CHILTON, P.J. \& FOSTER, S.S.D. 1995. Hydrogeological characterisation and water-supply potential of basement aquifers in tropical Africa. Hydrogeology Journal, 3(1):36-49.

COSGROVE, J. 1998. The role of structural geology in reservoir characterization. In: M.P. Coward, T.S. Daltaban, H. Johnson (ed.) Structural geology in reservoir characterization, Geological Society, London, Special Publication, 127: 1-13.

COSTA, W.D. 1986. Análise dos fatores que atuam no aquífero fissural - área piloto dos Estados da Paraíba e Rio Grande do Norte. Instituto de Geociências, Universidade de São Paulo, São Paulo, Tese de Doutoramento, 225p.

DAEE - DEPARTAMENTO DE ÁGUAS E ENERGIA ELÉTRICA. 1979. Estudo de Águas Subterrâneas - Regiões Administrativas 10 e 11-Presidente Prudente/Marília. Secretaria dos Serviços e Obras Públicas/DAEE, São Paulo, 3v.

DAEE - DEPARTAMENTO DE ÁGUAS E ENERGIA ELÉTRICA. 1981. Estudo de Águas Subterrâneas - Região Administrativa 5-Campinas. Secretaria dos Serviços e Obras Públicas/DAEE, São Paulo, 2v.

DAEE - DEPARTAMENTO DE ÁGUAS E ENERGIA ELÉTRICA. 1982. Estudo de Águas Subterrâneas - Região Administrativa
4-Sorocaba. Secretaria dos Serviços e Obras Públicas/DAEE, São Paulo, 2v.

DAVIS, S.N. \& TURK, L.J. 1963. Optimum depths of wells in crystalline rocks. Apresentado no National Water Well Exposition, San Francisco, Califórnia.

DAVISON, I. 1994. Linked fault systems: extensional, strike-slip and continental. In: P. L.Hancock, (ed.), Continental Deformation, Pergamon Press, UK, p. 53-100.

DEL REY, A.C. 1991. Fraturamento no nordeste do Estado de São Paulo e sua associação ao comportamento hidrogeológico regional. In: SBG, SIMPÓSIO NACIONAL DE ESTUDOS TECTÔNICOS, 3, Rio Claro, Boletim de Resumos, p. 197-198.

DOMENICO, P. \& SCHWARTZ, F. 1990. Physical and chemical hydrogeology. John Wiley \& Sons, Nova York, 824 p.

DUNNE, W.M. \& HANCOCK, P.L. 1994. Palaeostress analysis of small-scale brittle structures. In: P. L. Hancock (ed.), Continental Deformation, Pergamon Press, U.K., p. 101-120.

DUSSEL, M.; MOECK, I.; MUELLER, I.; SCHANDELMEIER, H. 2000. Preferential groundwater pathways along crittically stressed faults in carbonate rocks: (II) evidence from tectonic and eletromagnetic (AMT, RF-EM) data. EGS $25^{\text {th }}$ General Assembly, Nice. (CD-ROM)

ENGELDER, T.; FISCHER, M.P.; GROSS, M.R. 1993. Fracture Partitioning: failure mode as a function of lithology. In: Geological Society of America, Geological Aspects of Fracture Mechanics (A Short Course manual presented by the occasion of the Annual Meeting of the Geological Society of America), Boston, $281 \mathrm{p}$.

EVANS, J.P.; FORSTER, C.B., GODDARD, J.V. 1997. Permeability of fault-related rocks and implications for hydraulic structure of fault zones. Journal of Structural Geology, 19(11):1393-1404.

FERNANDES, A.J. 1997. Tectônica cenozóica na porção média da bacia do rio Piracicaba e sua aplicação à hidrogeologia de meios fraturados. Instituto de Geociências, Universidade de São Paulo, São Paulo, Tese de Doutoramento, 244 pp. 
FERNANDES, A.J. 2006. Fatores que influenciam a produção de poços em aqüíferos fraturados cristalinos e métodos de investigação. In: ABAS, CONGRESSO BRASILEIRO DE ÁGUAS SUBTERRÂNEAS, 14, Curitiba. (CD-ROM, 20 p.)

FERNANDES, A.J. \& ROULEAU, A. 2008. Simulação de deslocamentos em fraturas de basaltos da Formação Serra Geral (Ribeirão Preto, SP) e implicações para a sua transmissividade. In: ABAS, CONGRESSO BRASILEIRO DE ÁGUAS SUBTERRÂNEAS, 15, Natal. (CD-ROM, 16 p.)

FERNANDES, A.J. \& RUDOLPH, D. 2001a. The influence of Cenozoic Tectonics on the groundwater-production capacity of fractured zones: a case study in São Paulo, Brazil. Hydrogeology Journal, 9:151-167.

FERNANDES, A.J. \& RUDOLPH, D. 2001b. La influencia de la tectónica cenozoica en la productividad de agua subterránea em zonas fracturadas: aplicación a São Paulo, Brazil. Boletín Geologico y Minero, 112:77-92 (Número Especial).

FERNANDES, A.J.; PERROTA, M.M.; SALVADOR, E.; AZEVEDO, S.A; GIMENEZ FILHO, A. STEFANI, F.L.; PAULON, N. 2005. Aqüíferos Fraturados. In: G. Rocha, A.J. Fernandes, M. Mancuso (ed.) Mapa de Águas Subterrâneas do Estado de São Paulo, Nota explicativa, DAEE/IG/CPRM/IPT, p. 66-84.

FERNANDES, A.J.; MALDANER, C.; WAHNFRIED, I.; FERREIRA, L.M.R.; PRESSINOTTI, M.M.N.; VARNIER, C.; IRITANI, M.A.; HIRATA, R. 2006. Modelo conceitual preliminar de circulação de água subterrânea do aqüífero Serra Geral, Ribeirão Preto, SP. In: ABAS, CONGRESSO BRASILEIRO DE ÁGUAS SUBTERRÂNEAS, 16, Curitiba (CD-ROM).

FERNANDES, A.J.; MALDANER, C.; AZEVEDO SOBRINHO, J.M.; PRESSINOTTI, M. M. N.; WAHNFRIED, I.; FERREIRA, L.M.; VARNIER, C.; IRITANI, M.A.; HIRATA, R. 2008a. Estratigrafia e estruturas dos basaltos da Formação Serra Geral na região de Ribeirão Preto. In: SBG, SIMPÓSIO DE VULCANISMO E AMBIENTES ASSOCIADOS, 4, Foz do Iguaçu (CD-ROM).

FERNANDES, A. J.; WAHNFRIED, I.; VARNIER, C.; MALDANER. C.; PRESSINOT-
TI. M. M. N.; FERREIRA, L.M.; IRITANI, M.A.; HIRATA. R.; SHAPIRO, A.; ROULEAU A. 2008b. Modelo conceitual de circulação de água nos basaltos de Ribeirão Preto e como isto afeta a vulnerabilidade do SAG. In: SODERMA/DPRN/Governo do Estado de São Paulo /Ministério do Meio Ambiente, CONGRESSO DO AQÜÍFERO GUARANI, 2, Ribeirão Preto (CD-ROM)

FERRIL, D.A.; WINTERLE, J.; WITTMEIER, G.; SIMS, D.; COLTON. S.; ARMSTRONG, A; MORRIS, A.P. 1999. Stressed rock strains groundwater at Yucca Mountain, Nevada. GSA Today, 9(5):1-8.

FLORQUIST, B.A.; FOX, F.M. \& ASSOCIATES. 1972. Techniques for locating water wells in fractured crystalline rocks. Groundwater Field Reports, Annual National Water Well Association Convention, 24, Atlanta.

FREEZE, R.A. \& CHERRY, J.A. 1979. Groundwater. Prentice Hall, New Jersey, 604 pp.

GALE, J. \& ROULEAU, A. 1983. Characterizing and interpreting the geometry, permeability and porosity of fractures for repository evaluation. In: International Symposium on Field Measurements in Geomechanics, Zurich, Proceedings, p. 1343-1369.

GALLAS, J.D.F. 2003. Prospecção de água subterrânea em aqüíferos cristalinos com o emprego de métodos indiretos. Revista do Instituto Geológico, 24(1/2): 43-51.

GERNANDT, J.D. \& HEIDTMAN, J.P. 1997. Detailed pumping test to characterize a fractured bedrock aquifer. Ground Water, 35(4):632-637.

GUDMUNDSSON, A.1992. Formation and grouth of normal faults at the divergent plate-boundary in Iceland. Terra Nova, 4:464-471.

GUDMUNDSSON, A.; GJESDAL, O.; BRENNER S.L.; FJELDSKAAR, I. 2003. Effects of linking up of discontinuities on fracture growth. Hydrogeology Journal, 11(1):84-99.

GUSTAFSSON, P. 1994. Spot satellite data for exploration of fractured aquifers in a semi-arid area in Southeastern Botswana. Applied Hydrogeology, 2(2):9-18.

GUSTAFSSON, G. \& KRÁSNÝ, J. 1994. Crystaline rock aquifers: their occurrence, use and importance. Applied Hydrogeology, 2(2):64-75. 
HANCOCK, P.L. 1985. Brittle microtectonics: principles and practice. Journal of Structural Geology, 7(3/4):437-457.

HENRIKSEN, H.1996. Relation between topography and well yield in bore-holes in crystalline rocks, Sogn Fjordane, Norway. Ground Water, 33(4):635-643.

JOHNSON, C.D.; HAENI, F.P.; LANE, J.W; WHITE, E.A. 2002. Borehole-geophysical investigationof the University of Connecticut landefill, Storrs, Connecticut. USGS, Water Resources Investigations, Report 01-4033.

JOUANNA, P. 1993. A summary of field test methods in fractured rocks. In: J. Bear (ed.) Flow and contaminant transport in fractured rock, Academic Press, p.437-543.

KELLY, W.E. \& MARES, S. 1993. Applied geophysics in hydrogeological and engineering practice. Elsevier, 289 p.

KNOPMAN, D.S. \& HOLLYDAY, E.F. 1996. Variation in specific capacity in fractured rocks, Pennsylvania. Ground Water, 31(1):135-145.

LACHMAR, T.E. 1994. Application of fractureflow hydrogeology to acid-mine drainage at the Bunker Hill Mine, Kellogg, Idaho. Journal of Hydrology, 155:125-149.

LAMONTAGNE, E. 2001. Étude Hydromécanique d'une fracture en cisaillement sous contrainte normale constante. Department du Ressources Minérales, Université du Quebec à Chicoutimi, Thése Doctorat, $530 \mathrm{p}$.

LAWN, B.R. \& WILSHAW, T.R. 1975. Fracture of brittle solids. Cambridge Press University, $204 p$.

LOISELLE, M. \& EVANS, D. 1995. Fracture density distributions and well yields in Coastal Maine. Ground Water, 33(2): 190-196.

LONG, J. 1996. Rock fractures and fluid flow: contemporary understanding and applications. National Academy Press, Whashington, 551p.

MABEE, S.B.; HARDCASTLE, C.H.; WISE, D.U. 1994. A method of collecting and analyzing lineaments for regional scale fractured-bedrock aquifer studies. Ground Water, 32(6):884-894.

MADRUCCI, V. 2004. Prospecção de água subterrânea em terreno cristalino utilizando-se análise integrada de dados de sensoriamento remoto, geofísicos e técnicas de geoprocessamento, região de Lindóia, SP. Instituto de Geociências, Universidade de São Paulo, São Paulo, Tese de Doutoramento, 226 p.

MAZUREK, M.; LANYON, G.W.; VOMVORIS, S.; GAUTSCHI, A. 1998. Derivation and application of a geologic dataset for flow modelling by discrete fracture networks in low permeability argillaceous rocks. Journal of Contaminant Hydrology, 35:1-17.

MEISER \& EARL HYDROGEOLOGISTS. 1982. Use of fracture traces in water well location handbook. U.S. DEPARTMENT OF THE INTERIOR, Office of Water Research and Technology, Washington, $63 \mathrm{p}$.

MEJU, M. A. ; FONTES, S. L. ; OLIVEIRA, M. F. B. ; LIMA, J. P. R. ; ULUGERGERLI, E. U. ; CARRASQUILA, A. G. 1999. Regional aquifer mapping using combined VES-TEMAMT/EMAP methods in the semi-arid eastern margin of Parnaíba Basin, Brazil. Geophysics, 64(2): 337-356.

MENDES, J.M.B. \& DEHAINI, J. 1996. Avaliação da precisão de campanha geofísica a partir de dados de sondagens diretas e levantamento geofísico complementar. In: SBGf, WORKSHOP DE GEOFÍSICA APLICADA AO MEIO AMBIENTE, 1, Belém, Atas, p.15-17.

MENEGASSE, L.N. 1991. Estudo hidrogeológico das rochas metassedimentares do Grupo São Roque a NW da Grande São Paulo: critérios para locação de poços profundos. Instituto de Geociências, Universidade de São Paulo, São Paulo, Dissertação de Mestrado, 104 p.

MEYJERINK, A.M.J.; BANNERT, D.; BATELAAN, O.; LUBCZYNSKI, M.W.; POINTET T. 2007. Remote sensing applications to groundwater. UNESCO, IHP-VI, Series on Groundwater $\mathrm{n}^{\circ} 16$.

MORIN, R.H. \& SAVAGE, W.Z. 2003. Effects of crustal stresses on fluid transport in fractured rock: case studies from northeastern and sowthwestern USA. Hydrogeology Journal, 11:100-112.

MORIN, R.H.; CARLETON, G.B.; POIRIER, S. 1997. Fractured-aquifer hydrogeology from geophysical logs, The Passaic Formation, New Jersey. Ground Water, 35(2):328-338. 
MORIN, R.H.; SAVAGE, W.Z.; RIVARD, C. 2006. Hydrogeologic consequences of gravity-induced stresses along a ridge: example from Annapolis Valley, Nova Scotia. In: ARMA/ USRMS, U.S. Symposium on Rock Mechanics: 50 Years of Rock Mechanics - Landmarks and Future Challenges, 41, Golden, Colorado, 10 p. (CD-ROM)

MORIN, R.H.; SENIOR L.A.; DECKER, E.R. 2000. Fractured-Aquifer Hydrogeology from geophysical logs: Brunswick Group and Lockatong Formation, Pennsylvania. Ground Water, 38(2):182-192.

NAKAO, H.; FREITAS JÚNIOR, M.S.; ARAYA, J.A.M. 1983. Percolações preferenciais nas fundações das barragens sobre maciços basálticos. In: ABMS/ABGE/CBMR, SIMPÓSIO SOBRE GEOTECNIA DA BACIA DO ALTO PARANÁ, 1, Atas, (2): 425-430.

NOVAKOWSKI, K. 1995. Groundwater flow in fractured rocks. Waterloo Centre for Ground Water Research, Canada. Course Notes.46 p.

ODLING, N.E. 1997. Scaling and connectivity of joint systems in sandstones from western Norway. Journal of Structural Geology, 19(10):1257-1271.

ODLING, N.E.; GILLESPIE, P.; BOURGINE, B.; CASTAING, C.; CHLES, J.P.; CHRISTENSEN, N.P.; FILLION, E.; GENTER, A.; OLSEN, C.; THRANE, L.; TRICE, R.; AARSETH, E.; WALSH, J.J.; WATTERSON, J. 1999. Variations in fracture system geometry and their implications for fluid flow in fractured hydrocarbon reservoirs. Petroleum Geoscience, 5:373-384.

PARIZEK, R.R. \& SIDDIQUI, S.H. 1969. Determining the sustained yields of wells in carbonate and fractured aquifers. In: National Water Well Association Convention, San Francisco, St. Louis, Missouri.

PERROTTA, M.M. \& SALVADOR, E.D. 2002. Avaliação regional do potencial de produtividade de aqüíferos cristalinos em um Sistema de Informações Geográficas (SIG). In: SBG, CONGRESSO BRASILEIRO DE GEOLOGIA, 41, João Pessoa, Boletim de Resumos, p.166.

POLLARD, D.P. \& AYDIN, A. 1988. Progress in understanding jointing over the past century.
Geological Society of American Bulletin, 100:1181-1204.

PRICE, N.J.; COSGROVE, J.W. 1990. Analysis of geological structures. Cambridge University Press, Cambridge, 502 p.

QUADROS, E.F.; CORREAA FILHO, D.; TAIOLI, F.; PEREIRA, J.R. 1991. 3-D hydraulic tests on weathered-fractured basalt - Brazil. In: International Society of Rock Mechanics, International Congress on Rock Mechanics, Aachen, Proceedings.

RAMSAY, J. G. \& HUBER, M.I. 1987. The techniques of modern structural geology. Volume 2: Folds and Fractures. Academic Press, London, $700 \mathrm{pp}$.

REBOUÇAS, A.C. 1978. Potencialidade hidrogeológica dos basaltos da Bacia do Paraná no Brasil. In: SBG, CONGRESSO BRASILEIRO DE GEOLOGIA, 30, Recife, Anais, 6:2963-2976.

ROULEAU, A. 1994. Notes on direct fracture survey, In: Environmental Education Enterprises and the Associaton of Enginnering Geologists, Fractured rocks: characterization, flow and transport, Tucson, Arizona, Course Notes p. $280-282$.

ROULEAU, A. \& GALE, J.E. 1985. Statistical characterization of the fracture system in the Stripa granite, Sweden. International Journal of Rock Mechanics and Mining Sciences, 22(6):353-367.

ROUlEAU, A.; COUSINEAU, P.; DENIS, C.; LAPCEVIC, P. 1996. The estimation of hydraulic parameters of a fractured orthoquartzite formation at laboratory and field scales. In: M. Aubertin, F. Hassani, H. Mitri (ed), Rock Mechanics Tools and Techniques, NORTH AMERICAN ROCK MECH. SYMP., 2, Montreal, AA Balkema, p.13591366.

SAMI, K. 1996. Evaluation of the variations in borehole yield from a fractured Karoo Aquifer, South Africa. Ground Water, 34(1):114120 .

SIDLE, W.C. \& LEE, P.Y. 1995. Estimating local groundwater flow conditions in a granitoid: preliminary assessments in the Waldoboro Pluton Complex, Maine. Ground Water, 33(2):291-302. 
SILVA, A.B. 1984. Análise morfo-estrutural, hidrogeológica e hidroquímica no estudo do aquífero cárstico do Jaíba, norte de Minas Gerais. Instituto de Geociências, Universidade de São Paulo, São Paulo, Tese de Doutoramento, $156 \mathrm{p}$.

SINELLI, O. 1971. Água subterrânea no município de Ribeirão Preto. In: SBG, CONGRESSO BRASILEIRO DE GEOLOGIA, 25, São Paulo, Anais, p.17-34.

TAKAHASHI, A.T.; PERROTTA, M.M; SALVADOR, E.D.; INVERNEZZI, A. 2003. Hidrogeologia das Bacias de drenagem dos Rios Mogi-Guaçu e Pardo. In: CPRM / Secretaria de Estado do Meio Ambiente-SP, Projeto Mogi-Guaçu/Pardo, Relatório técnico, V.3, 92p.

TAVCHANDJIAN, O.; ROULEAU, A.; ARCHAMBAULT, G.; DAIGNEAULT, G.; MAROTTE, D. 1997. Geostatistical analysis of fractures in shearzones in the Chibougamau area: applications to structural geology. Tectonophysics, 269:51-63.

TIRÉN, S. 1991. Geological setting and deformation of a low-angle fracture zone at Finnsjon, Sweden. Journal of Hydrology, 126:17-43
TRESSOLDI, M. 1991. Uma contribuição à caracterização de maciços rochosos fraturados visando a proposição de modelos para fins hidrogeológicos e hidrogeotécnicos. Escola Politécnica, Universidade de São Paulo, São Paulo, Dissertação de Mestrado, 291p.

TROEGER, U.; DUSSEL, M.; MOECK, I.; SCHANDELMEIER, H. 2001. A new approach to the reconnaissance of groundwater flow in hard rocks: hydrotectonics. In: IAH, International Congress of IAH, 31, München. (CD-ROM)

UNESCO. 1984. Ground water in hard rocks: Studies and reports in hydrogeology. UNESCO, Paris.

YIN, Z.Y. \& BROOK, G.A. 1996. The topographic approach to locating high-yield in crystalline rocks: does it work? Ground Water, 30(1): 102.

ZAHNG, F.; ZHOU, Z.; HUANG, Y.; CHEN, Z. 2004. Determining the permeability of fractured rocks based on joint mapping. Ground Water, 42(4):509-515.

ZEMANEK, J.; GLENN, E.E.; NORTON, L.J.; CALDWELL, R.L. 1970. Formation evaluation and inspection with the borehole televiewer. Geophysics, 35:254-269.

Endereço dos autores:

Amélia João Fernandes - Seção de Hidrogeologia, Instituto Geológico, Secretaria do Meio Ambiente do Estado de São Paulo, Avenida Miguel Stéfano, 3900, CEP 04301-903, Água Funda, São Paulo, SP. E-mail: ameliajf@igeologico.sp.gov.br 